\title{
Dictynna
}

Dictynna

Revue de poétique latine

$5 \mid 2008$

Varia

\section{Une poétique du vœu : inspiration poétique et mystique impériale dans le poème XIX (et quelques autres) d'Optatianus Porfyrius}

Marie-Odile Bruhat

\section{OpenEdition}

Journals

Édition électronique

URL : http://journals.openedition.org/dictynna/369

DOI : 10.4000/dictynna.369

ISSN : 1765-3142

Référence électronique

Marie-Odile Bruhat, « Une poétique du vœu : inspiration poétique et mystique impériale dans le poème XIX (et quelques autres) d'Optatianus Porfyrius », Dictynna [En ligne], 5 | 2008, mis en ligne le 25

novembre 2010, consulté le 11 septembre 2020. URL : http://journals.openedition.org/dictynna/369 DOI : https://doi.org/10.4000/dictynna.369

Ce document a été généré automatiquement le 11 septembre 2020.

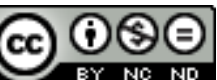

Les contenus des la revue Dictynna sont mis à disposition selon les termes de la Licence Creative Commons Attribution - Pas d'Utilisation Commerciale - Pas de Modification 4.0 International. 


\title{
Une poétique du vœu : inspiration poétique et mystique impériale dans le poème XIX (et quelques autres) d'Optatianus Porfyrius
}

\author{
Marie-Odile Bruhat
}

Le poème XIX composé par Publilius Optatianus Porfyrius ${ }^{1}$ à l'occasion de la deuxième célébration en juillet 326 à Rome des vingt ans de règne de l'empereur Constantin apparait comme une brillante synthèse des formes de poésie visuelle mises en pratique par le poète. Rappelons que la fortune de cette poésie fut et reste singulière. La majorité des poèmes conservés, que la tradition manuscrite nous a légués sous la forme d'un recueil intitulé Panégyrique de Constantin, est consacrée à l'éloge d'un unique destinataire, Constantin, et jalonne le parcours politique de ce dernier, depuis le partage du pouvoir avec Licinius jusqu'à son élimination et la réunification de l'empire sous l'égide de la famille constantinienne. Après avoir joui de la faveur impériale pour ses offrandes poétiques, Optatien fut condamné à l'exil pour une raison et à une date qui restent incertaines. La Chronique de Jérôme atteste que son retour en grâce fut gagné par l'envoi de poèmes à l'empereur : « Porfyrius, après avoir envoyé à Constantin un livre remarquable, est libéré d'exil $»^{2}$. Le pardon impérial fut si complet qu'Optatien occupa ensuite à deux reprises la fonction de préfet de la ville de Rome. Pourtant, après cette embellie célébrée par un ultime poème, nous n'avons plus de trace ni du haut fonctionnaire, ni de sa poésie. Le silence se fait autour de lui, au point que deux siècles et demi plus tard, Venance Fortunat, commentant ses propres poèmes figurés, peut sans vergogne affirmer qu'il en est l'inventeur, quand il n'est que trop évident qu'il imite directement les poèmes de son prédécesseur. $^{3}$ Il est vrai que les poèmes d'Optatien étaient considérés comme païens ${ }^{4}$, et que la «christianisation » du procédé figuratif par Venance Fortunat permit sans doute l'essor de ce genre de poésie et le regain d'intérêt pour Optatien, considéré comme son inventeur. L'époque carolingienne le mit particulièrement à l'honneur, et Raban Maur sut à la fois 
reconnaître sa dette à l'égard du poète constantinien ${ }^{5}$ et transformer à son tour cet héritage jusqu'à en faire un art tout personnel.

2 Le parcours poétique d'Optatien est, à l'image de sa carrière et de la réception de son oeuvre, fait pour nous d'ombre et de lumière. La tradition manuscrite l'éclaire peutêtre d'un faux jour, car rien ne permet d'affirmer que le groupe de poèmes conservés reflète fidèlement la production poétique d'un auteur remarquablement discret sur luimême et au sujet duquel manquent malheureusement des témoignages extérieurs. Avons-nous conservé l'ensemble des poèmes, et si ce n'est pas le cas, quelle proportion est parvenue jusqu'à nous? Surtout, la proportion des poèmes constantiniens dans les poèmes conservés est-elle conforme à la réalité? Le uolumen mentionné par Jérôme comportait-il uniquement des poèmes d'exil, ou regroupait-il tous les poèmes constantiniens en une sorte d'anthologie conçue par son auteur et dont la tradition manuscrite garderait la trace? Ces incertitudes sont d'autant plus regrettables qu'une juste estimation de la poésie d'Optatien requiert des hypothèses sur l'invention et la transformation des procédés figuratifs mis en œuvre par le poète, hypothèses qui s'appuient sur le corpus existant et peuvent par conséquent être faussées.

3 Sur cet horizon instable apparaissent du moins quelques points fixes : le poème XIX est l'un d'eux. Contrairement à beaucoup des poèmes d'Optatien, on peut le dater avec certitude, et cette datation lui confère un statut particulier, puisqu'elle amène à considérer qu'avec le poème $\mathrm{XX}$, également composé à l'occasion de la réitération à Rome de la célébration des Vicennales, il conclut le uolumen envoyé d'exil à l'empereur. Ainsi, non seulement les poèmes XIX et XX bénéficient d'une technique déjà éprouvée, mais il ne fait aucun doute qu'Optatien a voulu faire d'eux le sommet de son art, de la même manière que la venue à Rome de Constantin pour y fêter l'anniversaire de son pouvoir et son triomphe sur Licinius revêtait une solennité exceptionnelle. La composition de deux poèmes pour célébrer une même circonstance, loin d'être une redondance, traduit une intention manifeste. Chacun des poèmes atteint un degré de virtuosité extraordinaire dans le genre de poésie figurée qui est le sien: poème "carré », à l'intérieur duquel des lettres de couleur différente dessinent une figure, pour le poème XIX, poème "à contour ", dans lequel la longueur des vers, variant en fonction du nombre de lettres, dessine la silhouette d'un objet, pour le poème XX. Le poème "carré ", quelles que soient les hypothèses sur sa genèse, est une authentique invention d'Optatien. Le poème "à contour ", hérité des modèles alexandrins ${ }^{6}$, a été très profondément remanié, puisqu'Optatien a substitué à la polymétrie des poètes grecs la règle du respect d'un mètre unique, l'hexamètre dactylique, et remplacé le procédé approximatif qui consistait à adapter l'écriture à un cadre préalablement dessiné par une technique rigoureuse dans laquelle la lettre constitue l'unité de mesure.

4 Or les difficultés de réalisation de chacun des deux genres de figure sont ici poussées à leur paroxysme. Pour le poème $\mathrm{XX}$, la double règle que s'impose Optatien dans le poème à contour - un mètre unique, la lettre comme unité de mesure - l'amène, pour dessiner les tuyaux de l'orgue, à composer vingt-six hexamètres qui, en partant d'un premier hexamètre de vingt-cinq lettres, croissent d'une lettre par hexamètre jusqu'au vingt-sixième et dernier hexamètre qui compte cinquante lettres, soit le double du premier. La prouesse est remarquable, et le passage du simple au double veut évidemment le souligner; l'assemblage des mots et du rythme d'où naît l'hexamètre ne constitue pas pour les latins, de l'aveu même des poètes, un matériau aisément 
malléable. Le sommier de l'orgue est quant à lui dessiné par vingt-six dimètres iambiques catalectiques comptant tous dix-huit lettres, tandis que le clavier est figuré par une formule de vœux adressée à Auguste vainqueur. La figure du poème XIX combine tous les procédés mis en œuvre par Optatien dans différents poèmes carrés. Les vers brochés (uersus intexti) dessinent un navire : coque, poupe, proue, gouvernail, rames; le mât et la vergue, eux aussi dessinés par des vers brochés, reproduisent en outre le chrisme constantinien, chi et rhô entrelacés ; les lettres qui dessinent le mât, la vergue et le gouvernail forment grâce à l'ambivalence des majuscules un distique grec ; la voile est constituée par des lettres du texte qui dessinent les grandes lettres d'une inscription abrégée : VOT ; le signe XX des Vicennales est inscrit sur la coque du navire et permet en outre de multiplier les trajectoires de lecture : grâce à la combinatoire, chacun des cinq hexamètres constitués par les lettres qui dessinent proue, coque, poupe et rames peut être lu en suivant quatre chemins différents, les vingt possibilités de lecture ainsi obtenues consonant avec le signe des Vicennales. Là encore, le niveau de contrainte que s'est imposé Optatien est exceptionnel.

5 Le poète a donc voulu clore son recueil par deux compositions qui attestent sa grande virtuosité technique, mais qui soient aussi comme une parfaite synthèse de son art poétique. Les deux poèmes sont à cet égard inséparables et sans aucun doute complémentaires. Mais c'est sur le poème XIX que nous nous arrêterons ici, car il illustre la cohérence d'une entreprise poétique que la critique moderne a souvent choisi de minimiser. Maniérisme, affectation, artificialité, gratuité : les termes furent nombreux pour disqualifier non le procédé figuratif dont on ne pouvait que saluer la réussite, mais l'idée d'un projet poétique au sens plein du terme. Optatien serait un versificateur de génie doublé d'un courtisan opportuniste. Sa poésie, miroir complaisant du pouvoir, serait en somme ingénieuse, mais sans profondeur et dépourvue d'une dimension réflexive. Ceux qui prennent la peine de lire les poèmes d'Optatien mesurent pourtant déjà le sérieux d'une poésie réellement engagée dans son temps, capable d'accompagner le pouvoir en pleine gestation de Constantin. Or cela n'est pas rien! Seule notre connaissance rétrospective du devenir de ce pouvoir permet à vrai dire d'assimiler à un pur opportunisme l'intelligence des mutations alors en cours. Leur lisibilité était certainement beaucoup plus réduite pour les contemporains de Constantin, confrontés à une volonté politique totalement inédite. Il nous apparaît aujourd'hui clairement que Constantin sut inscrire une nouveauté radicale - un empire chrétien - dans un cadre politique et religieux hérité des siècles précédents, celui d'une théologie du pouvoir fondée sur la victoire; mais cette transformation fut menée de manière progressive, prudente, et soucieuse de ménager un équilibre entre les sujets païens et chrétiens de l'empire. Dans les années de transition pendant lesquelles s'exerce l'activité poétique d'Optatien, cette prudence même et cet équilibre ne devaient guère faciliter l'interprétation par les uns et les autres de la position impériale. Il y a, reconnaissons-le, plus que de l'opportunisme dans le conformisme politique d'Optatien, tant il est vrai que se conformer à la position constantinienne demandait alors, outre une probable proximité avec le pouvoir, une réelle intelligence politique.

6 Notre propos est précisément de montrer que l'intelligence qu'Optatien a du pouvoir constantinien ne s'exprime pas seulement dans la thématique de ses textes, mais aussi dans ses choix formels, et qu'elle participe d'une dimension réflexive de sa poésie. En d'autres termes, la célébration impériale nourrit et enrichit le projet poétique: Optatien, qui a d'abord simplement adapté ses jeux poétiques à son nouveau 
destinataire, a progressivement conçu une forme poétique qui fait fusionner de la manière la plus éclatante dans le poème XIX certains traits spécifiques de l'idéologie constantinienne avec les traits non moins spécifiques d'une écriture caractérisée par l'ambition que son auteur soit reconnu non seulement comme poiètès, mais aussi comme uates. Cette ambition s'inscrit dans un cadre précis, défini par Optatien en des termes très clairs : il veut être le poète inspiré de Constantin, c'est-à-dire celui dont la production poétique reflète le soutien accordé par la sphère divine au pouvoir de l'empereur. La référence à l'inspiration poétique revêt dès lors une signification proprement politique.

7 Au départ de la réflexion d'Optatien, il y a sans doute ce constat: la technicité du procédé figuratif qu'il avait élaboré risquait de sembler peu compatible avec les prestiges de l'inspiration. La virtuosité même de cette poésie l'expose en effet à être considérée comme un "tour de force", dans lequel ne peut entrer aucun élan imputable à l'enthousiasme. Il semble qu'Optatien ait mesuré ce risque, et tenté d'y remédier. Les références aux Muses, à Apollon, et à toute la géographie mythique de l'inspiration sont très présentes dans ses textes. Non que le poète ait renoncé à vanter son travail de poiètès. L'argument est plutôt le suivant : la difficulté pour l'auteur de se plier aux contraintes qu'il a ajoutées aux règles habituelles de la poésie est telle que, sans l'aide divine, il n'en serait pas venu à bout. Optatien nous montre les Muses à l'ouvrage, tissant ses vers sous l'autorité bienveillante de Phébus : la part faite à cette évocation est même considérable dans certains poèmes, et rivalise alors avec l'éloge de l'empereur. Pourtant il n'y a pas de tension, car la référence à l'univers mythique de l'inspiration participe de manière essentielle de l'éloge impérial. La question du statut d'une poésie entièrement dédiée à l'empereur n'est évidemment pas indifférente à son objet: un statut mythique tel que le postule Optatien confère à l'éloge une grandeur digne du destinataire, et de ce fait il fonctionne comme un topos presque obligé. Mais dans le cas de Constantin, ce postulat répond en outre à une attente précise. On s'accorde à reconnaître que l'empereur a eu l'ambition de promouvoir une politique culturelle, dont le témoignage le plus marquant est le Discours à l'assemblée des saints. À l'évidence, Constantin, quelle que fût sa culture littéraire, était très conscient du prestige de la poésie et du bénéfice idéologique qui pouvait en être tiré. C'est cette convergence entre l'attente impériale et la "proposition " poétique d'Optatien que nous voudrions préciser ici. Et s'il nous semble que le poème XIX est une illustration privilégiée de cette convergence, encore convient-il d'abord d'en rechercher les traces, ou plutôt les étapes, dans les poèmes qui le précèdent, ce qui ne se fera pas sans quelques détours.

8 La première question qui se pose est celle de la pertinence de la référence à des divinités païennes de l'inspiration dans des textes directement adressés à un empereur qui, depuis sa victoire de 312 sur Maxence, se réclame du soutien du Dieu des chrétiens. Fixons d'abord les limites de la réponse qui peut être apportée ici : il ne s'agit pas de revenir sur la «question" constantinienne, dans la mesure où cette question semble aujourd'hui résolue pour l'essentiel. La conversion de Constantin n'est plus sérieusement mise en doute, seules ses modalités exactes font encore débat. Or la poésie d'Optatien peut et doit être considérée comme un témoin non négligeable dans ce débat. On ne peut en effet douter du caractère officiel des relations entre le poète et l'empereur: le poème de dédicace à l'empereur du corpus envoyé d'exil rappelle qu'avant sa disgrâce, les poèmes d'Optatien étaient remis directement à Constantin, et que leur apparence matérielle attestait l'agrément de ce dernier. Écrits en lettres d'or 
et d'argent sur un fond pourpre, ils touchaient de trop près à la majesté impériale pour ne pas jouir d'un statut officiel. La mention dans la Chronique de Jérôme du rappel d'exil d'Optatien en récompense de l'envoi de ses poèmes, puis ses deux préfectures urbaines ne permettent pas non plus de minimiser la relation entre le poète et l'empereur. À cela s'ajoute le témoignage d'Optatien dans un poème d'avant l'exil, le poème $\mathrm{X}$. Le poète $\mathrm{y}$ évoque directement la faveur impériale :

Sic parua locuto

amplius en, iudex, dominus, tot munera summa

tantaque concedis. Tu mentem dicere donis

inuitas laudis cum munere; sic uaga primis,

haud audita ligas. Nec dictis laesa Camena

audet magnanimo uati noua uincula mentis

iussa dare, creuitque meo correpta fauore.

«À celui qui t’a adressé de si pauvres écrits, voici qu'avec plus de largesse tu accordes, juge et seigneur, tant de dons éminents, des dons si grands! C'est toi qui, par tes présents, accompagnés de la faveur de tes éloges, invites mon esprit à te chanter. Ainsi, tu lies des paroles d'abord errantes, inouïes. Et la Camène, que n'ont pas blessée tes paroles, ose donner comme on l'en a priée au généreux poète les nouveaux liens de l'esprit et, saisie par la faveur dont je jouis, s'en est trouvée grandie. $»^{7}$

Optatien évoque clairement la réception de ses poèmes par Constantin : ce dernier non seulement les approuve et les récompense, mais il encourage leur production. Cette approbation vaut donc aussi pour ce qui, plus qu'une simple référence, est une véritable mise en scène des Muses et d'Apollon au long des textes. Cela est d'autant plus vrai que les deux poèmes dans lesquels Optatien présente la faveur impériale comme très active sont aussi deux poèmes dans lesquels la mise en scène des Muses et d'Apollon occupe une place importante et même, pour l'un d'eux, prépondérante. Dans le poème $\mathrm{X}$, qui vient d'être cité, l'auteur emploie la moitié de ses vers à dire l'origine divine de son inspiration. Mais le poème III, véritable manifeste poétique, est entièrement consacré à l'exposition de son art par le poète, ce qui est un cas unique dans le corpus des textes conservés. Nous le citons donc dans son intégralité :

"Je brûlerais de modeler par le pouvoir divin des Muses ton visage, ô père bienfaisant de l'univers, pour accomplir en vers mon office et mes vœux, si les règles ne s'opposaient pas à l'ordre de Phébus. Ils chantent les hauts faits, ceux à qui le clément pouvoir de l'Aonie donne de jouir de l'état de poète. Mais ensuite, en relevant son courage par les dons faits à ses poèmes, en incitant sa bouche à faire retentir les vers, c'est toi qui inspires l'esprit de ton poète; c'est toi qui appelles sans cesse la joie sur ta personne, ô divin empereur. Toi qui encourages de toutes les manières la Camène à prononcer de savantes paroles, tu accueilles radieux les vœux pour ta prospérité, afin qu'ils s'accomplissent. Le doux souverain de l'Olympe veille sur ton siècle paisible avec un amour particulier. Dorénavant ton âge d'or, victorieux Constantin, règne sur l'univers entier. Qui veut le célébrer en mètres libérés des contraintes de l'entrelacs met en branle les Muses en une grande troupe. Calliope au contraire, qui tisse difficilement mes vers à l'aide des rythmes peints de Phébus, se réjouit si le dieu de Délos vient seconder ses vœux, pour que la Muse favorise les paroles brochées suivant un chemin identique et marque du sceau de ses vers les siècles d'or. Mais les filles de l'Aonie, confiantes en leur vœu, entraînent vers la joie un esprit qui t'est consacré, et l'engagent à parler avec hardiesse en empruntant des chemins détournés. Plus strictes sont les règles auxquelles elles doivent plier leurs paroles, mieux elles vous célèbrent, toi, prince illustre, et tes guerres si grandes, avec toute leur âme et de toute leur foi, par la voix inspirée de ton poète. Buvant à la source de Pégase, elles pratiquent un poème nouveau, et veulent maintenant, par l'entrelacement, célébrer comme il le mérite un pouvoir 
exceptionnel, car on a du plaisir à accomplir une si grande tâche et à chanter des exploits éminents en empruntant des sentiers rocailleux. Oeuvre étonnante de l'esprit que de brocher le poème de vers qui suivent des parcours variés. Avec difficulté, enclos en d'étroites limites, que l'esprit ingénieux présente désormais les visions noueuses de son art. Pourtant, ayant osé parler d'une pareille voix, il est tout agité, et ne croit pas produire ainsi poème digne de ses vœux, chantant sous une telle loi. Vœux qu'une page unique, encor qu'issue de l'Hélicon, accomplira, don de notre affection, page ornée à travers les rythmes poétiques d'un tissu bigarré de lettres. "

Les vers brochés forment le texte suivant :

«Si la Muse peut reproduire le visage d'Auguste par un tel poème, en observant les lois et du vers et du mètre, cette page, ornée à travers les rythmes poétiques d'un tissu bigarré de lettres, osera vaincre les portraits d'Apelle. Grande sera l'œuvre accomplie, si une Camène féconde assiste le poète dans son entreprise, marquant $d u$ sceau de ses vers l'âge d'or. " ${ }^{8}$

11 La figure censée représenter le uultus de Constantin est une figure géométrique : une croix formée par le dix-huitième vers du poème (qui en compte trente-cinq) et par un mésostiche composé par la dix-huitième lettre des vers (qui comptent tous trente-cinq lettres) partage le poème en son milieu horizontalement et verticalement; quatre hexagones qui s'inscrivent de part et d'autre de ces lignes médianes dessinent à leur tour une croix inclinée. Le résultat est le suivant: deux croix entrelacées, dans lesquelles il paraît vain de chercher la représentation des traits physiques du visage impérial. Derrière la forme géométrique, abstraite du dessin, il faut sans doute discerner la signification symbolique: puisque le visage est traditionnellement considéré comme "l'image de l'âme ", le motif de la croix pourrait renvoyer à la foi chrétienne de Constantin. ${ }^{9}$ Rien dans le poème d'Optatien ne vient confirmer ou infirmer cette hypothèse, même si la mention du "doux souverain de l'olympe » est plutôt dissonante. ${ }^{10}$

Le véritable enjeu du poème est éclairé par la référence à Apelle dans les vers brochés. Le poète déclare que s'il peut mener à bien son projet de représenter le visage d'Auguste par son poème, tout en respectant les règles métriques, la page ainsi offerte à l'empereur l'emportera sur les portraits d'Apelle. Ne nous y trompons pas : ce n'est pas le succès de ce poème particulier qui est seul en question. La véritable revendication est implicite: de même qu'Apelle fut le peintre attitré d'Alexandre, celui auquel était réservée la représentation du visage du souverain, de même Optatien aspire à être le poète de Constantin, son poète officiel. Ainsi s'explique la singularité - pour ne pas dire le paradoxe - d'un poème dont la figure concerne la personne même de l'empereur, et dont le texte, au lieu d'éclairer le sens énigmatique de la figure, commente la démarche poétique de son auteur. Loin d'être étrangers l'un à l'autre, texte et image sont complémentaires : le poète définit grâce à eux la nature et la finalité de son œuvre. Deux thèmes s'entrecroisent dans le texte : celui de la nature inspirée de cette poésie et celui de son allégeance à l'empereur. Phébus est invoqué comme l'auctor de toute poésie inspirée :

Gesta canunt, quos Aonium placabile numen

uatis sorte frui dat ${ }^{11}$.

13 Mais ensuite, c'est Constantin qui est présenté comme l'auctor de la poésie porfyrienne, lui qui en est doublement l'inspirateur, comme sujet, en faisant naître par les bienfaits qu'il accorde le désir de le louer, et comme agent, en encourageant la parole poétique : 
donis carminis ex hoc

sustollens et uersu instigans ora sonare,

tu mentem inspiras uatis; tu gaudia semper

in te, sancte, uocas ${ }^{12}$.

Flatterie sans grande originalité, objectera-t-on. Certes, mais de même qu'il tisse les vers horizontaux de son poème avec les vers brochés qui dessinent la figure, Optatien tisse le thème de l'inspiration poétique avec celui de l'inspiration politique, et la flatterie se mue en un programme. Optatien évoque le soutien divin au pouvoir de l'empereur sous la forme très vague d'un " doux souverain de l'olympe », et célèbre un âge d'or constantinien étendu par la victoire aux dimensions de l'univers. Ce sont alors Calliope et le dieu de Délos qui sont chargés d'authentifier cet âge d'or par le travail poétique :

Aurea iam toto, uictor, tua saecula pollent,

Constantine, polo. Haec nexus lege solutis

dicturus metris magno mouet agmine Musas,

at mea uix pictis dum texit carmina Phoebi

Calliope modulis, gaudet, si uota secundet

Delius, intexta ut parili sub tramite Musa

orsa iuuet, uersu consignans aurea saecla ${ }^{13}$.

Le sceau poétique (uersu consignans) qui a pour fonction d'attester l'âge d'or constantinien est redoublé par le fait que le dix-huitième vers, qui clôt le passage cité, est aussi l'un des vers brochés, constituant avec le mésostiche l'unité de sens suivante :

Grandia quaerentur, si uatis laeta Camena.

Orsa iuuet, uersu consignans aurea saecla ${ }^{14}$.

16 À travers la parole poétique, Phébus devient l'auctor, le garant, du pouvoir constantinien lui-même, un pouvoir élevé à la dignité du règne de l'âge d'or. L'âge d'or est ici seulement mentionné. Mais Optatien a consacré trois poèmes, les poèmes XI, XII et XIV, à célébrer la victoire de Constantin sur Licinius comme l'avènement de la justice et le retour de l'âge d'or dans un empire réunifié. Nous ne pouvons que résumer brièvement notre hypothèse de lecture de ces trois poèmes : ils répondent, au moment crucial du conflit avec Licinius, à un programme de propagande impulsé par Constantin, dont témoigne aussi la dédicace à l'empereur ajoutée par Lactance à une nouvelle édition de ses Institutions divines..$^{15}$ La justice y est clairement assimilée au christianisme, dont Constantin est le champion face à un Licinius présenté comme son persécuteur. Or, les trois poèmes d'Optatien présentent une image à première vue très composite de la justice et de l'âge d'or. Le poème XII, dont il est difficile de savoir s'il appelle seulement de ses vœux la réunification de l'empire ou s'il célèbre son imminence, conserve des accents familiers aux lecteurs païens :

Mox carus Eois

tot populis pia iura feres, et solus in omni

Augustus mundo sparges et in ultima numen.

Sol tibi felices faciet spes perpete nutu :

ars bona iustitiae et diuum uicina decori

largi dona boni caelo capit ; influit illuc

uota quod optarint pietatis. Cana subibit

sancta Ceres; tellus reddit Bacheia lapsa

riuis dona suis ; non Euri e flumine turbant

enormes pelagus.

«Bientôt, cher à tant de peuples d'Orient, tu leur apporteras de pieuses lois et, seul

Auguste dans le monde entier, tu répandras ta puissance jusqu'aux confins de 
l'univers. Le Soleil favorisera tes espérances par un assentiment perpétuel. Le bon exercice de la justice, proche de la gloire des dieux, reçoit du ciel des dons d'un avantage considérable; vers elle afflue tout ce que des vœux pieux ont pu souhaiter. L'antique et auguste Cérès s'avancera; la terre rend les présents de Bacchus qui coulent dans ses ruisseaux; les énormes Eurus ne troublent pas la mer de leur souffle. $»^{16}$

Les vers brochés développent la propagande impériale sur la justice et l'âge d'or :

Certa salus rerum, proles inuicta Tonantis.

Orbi tu renouas felicis tempora saecli.

Aurea iustitia terris insignia donas.

« Du monde sûr salut, descendance invaincue du maître du tonnerre, tu fais renaître à l'univers les temps d'un âge heureux, et tu donnes à la terre les signes d'or de la justice.»

18 L'apostrophe à la «descendance invaincue du maître du tonnerre » (proles inuicta Tonantis) dans le texte broché, en même temps que la référence à l'assentiment perpétuel du Soleil (Sol tibi... perpete nutu) dans le poème, renvoient au dieu solaire, dont Constantin, à la suite de son père Constance, a d'abord fait son comes. L'image du dieu, avec la tête radiée, apparaît sur les monnaies constantiniennes, avec la légende Soli inuicto comitit $^{17}$. L'épithète inuictus fera partie de la titulature impériale jusqu'à la victoire sur Licinius, après laquelle elle sera remplacée par uictor. Sol lui-même avait disparu des monnaies dès avant cette date ${ }^{18}$. Le poème XII pourrait faire écho à trois séries de solidi émises en 313-314, 313-317 et 315-317 : sur l'avers est représenté Sol, tendant à Constantin la statuette de la Victoire avec globe et couronne, avec la légende Felicitas perpetua saeculi ; sur le revers, la tête de l'empereur avec une couronne de lauriers est accompagnée de la légende Constantinus P(ius) F(elix) Aug(ustus) ${ }^{19}$. Le vers 6 de notre poème ainsi qu'un des vers brochés consonnent avec le message de ces monnaies : Sol tibi felices faciet spes perpete nutu (v. 6); orbi tu renouas felicis tempora saecli (v. i.).

19 Le poème XIV, postérieur au poème XII, célèbre avec lyrisme un âge d'or advenu, mais le soutien divin a changé de nature : c'est le monogramme du Christ qui s'affiche sur la page. Il faudrait ici encore citer le poème entier, mais nous nous contenterons de son début et de sa fin, qui assimilent le bonheur de l'empire pacifié et réunifié au retour de la justice et au règne de l'âge d'or.

Sancte, decus mundi ac rerum summa salutis,

lux pia terrarum, te solo principe saeclis

inmensum gaudere bonis datur. Aurea uenit

summo missa deo, fusis, pater alme, tyrannis,

iustitia in terras et gloria candida ueri.

(...)

Tu pius et iusti uere memor, inclite, laetis

da responsa ; bono semper mitissimus orbis

impertire tuum clementer et addito numen.

Sint mage felices, pariter quos, alme, tuere,

et reparata iugans maesti diuortia mundi,

orbes iunge pares; det leges Roma uolentis

principe te in populos; miti felicius aeuo

omnia laetentur florentibus aurea rebus.

«Divin, gloire du monde et salut suprême de l'univers, lumière pieuse de la terre, avec toi pour seul prince, il est donné aux heureux siècles de se réjouir immensément. Envoyés par le dieu souverain, maintenant qu'ont été terrassés les 
tyrans, viennent sur la terre, père bienveillant, la justice d'or et la gloire éclatante de la vérité.

(...)

Toi qui es pieux et vraiment fidèle à la justice, donne, prince, aux peuples en liesse une réponse; plein de douceur, consacre et attache toujours avec clémence ta divine volonté au bien de l'univers. Qu'ils soient plus heureux, père bienveillant, ceux sur qui tu veilles pareillement; répare le divorce du monde affligé, en l'unissant, joins deux mondes égaux. Que Rome, sous ton principat, donne ses lois aux peuples qui le souhaitent; que dans la douceur du siècle, tout soit d'or et se réjouisse d'un bonheur plus grand, dans l'univers florissant. ${ }^{20}$

Le texte broché est le suivant :

Summi dei auxilio nutuque perpetuo tutus. Orbem totum pacauit trucidatis tyrannis.

Constantinus pius et aeternus imperator.

Reparator orbis.

«Grâce à l'aide de la divinité suprême et avec son assentiment perpétuel, Constantin, empereur pieux et éternel, restaurateur du monde, a pacifié l'univers après avoir massacré les tyrans. "

21 La célébration de l'aurea iustitia est directement mise en relation avec la victoire de Constantin sur les tyrans. Pourquoi ce pluriel ? La figure du poème ainsi que le texte broché qui la dessine apportent une réponse évidente: le chrisme comme le texte évoquent, derrière le «tyran » de l'Orient Licinius, qui vient d'être éliminé, l'ancien «tyran » de l'Occident hostile au christianisme, Maxence. L'« invention » du chrisme date de la victoire sur Maxence en 312, victoire solennisée par l'édification d'un arc triomphal, dont la dédicace eut lieu en 315, en présence de l'empereur venu à Rome pour célébrer ses Décennales. Sur l'arc, une inscription célèbre la victoire de Constantin sur Maxence en ces termes : quod instinctu diuinitatis mentis magnitudine cum exercitu suo tam de tyranno quam de omni eius factione uno tempore iustis rempublicam ultus est armis...

De Sol dans le poème XII au summus deus du poème XIV, une constante demeure : l'éloge de la justice et de l'âge d'or constantiniens répond à un programme de propagande impériale. Or ni les Muses ni Apollon n'apparaissent dans ces poèmes ; dans l'un comme l'autre, le propos politique a exclu le propos poétique. La situation est presque inverse dans le poème III ; presque seulement, car le propos politique n'en est pas absent, mais il est orienté vers le propos poétique. L'âge d'or constantinien n'est pas célébré pour lui-même, mais en ce qu'il justifie l'élan poétique, dans une sorte d'échange de dons qui témoigne du bonheur des temps : bonheur procuré par Constantin à l'univers entier, et particulièrement à son poète, et en retour, bonheur d'offrir des vœux poétiques pour à la fois célébrer et pérenniser cet âge d'or. Lorsque le poète fait de l'empereur son inspirateur en ces termes :

Tu quiuis docta Camenae

edere dicta fauens, tu laetus uota secunda,

ut rata sint, audis. ${ }^{21}$

il présente sa poésie comme savante et votive. Or l'autorité sur laquelle s'appuient à la fois cette science et l'efficacité de ces vœux est Phébus, encore désigné comme « le dieu de Délos ». Quelle valeur peut avoir pour l'empereur cette caution divine, au regard des soutiens divins qu'il a lui-même désignés, et dont les poèmes XII et XIV se sont faits l'écho? Nous ne répondrons pas encore ici, mais poserons seulement ce constat: le dieu solaire du poème XII et le dieu suprême du poème XIV s'excluent d'un poème à l'autre, tandis que le poème III fait cohabiter une figure dont la connotation chrétienne 
paraît s'imposer et la référence à un dieu de la poésie qui n'est pas sans affinités avec le dieu solaire.

Le tissage du politique et de la poétique ébauché autour du thème de l'âge d'or est à l'œuvre dans la description du travail poétique qui constitue la plus grande partie du poème III. Optatien y explique ses choix formels. Il souligne et en même temps légitime la nouveauté et la difficulté de sa poésie. Au couple formé par Calliope et le dieu de Délos se substitue une nouvelle alliance, celle de la troupe des « filles de l'Aonie » avec le poète dévoué à Constantin. Ici encore, arguments poétique et politique sont étroitement liés: l'ampleur des contraintes formelles auxquelles les Muses doivent se plier est proportionnelle à la grandeur des guerres qu'elles veulent célébrer par la voix du poète inspiré ; c'est pour s'adapter à un pouvoir hors du commun qu'elle doivent pratiquer un genre nouveau de poésie, et emprunter des chemins à la fois détournés et escarpés, ceux des uersus intexti. Toutes proportions évidemment gardées, on songe, devant cette apologie de la poésie porfyrienne, à la célèbre apologie du poème lucrétien. La ferveur avec laquelle le poète épicurien se réclamait du patronage des déesses de l'inspiration pouvait sembler aussi paradoxale que la conviction avec laquelle Optatien convie les Muses et Apollon à favoriser une poésie dédiée à un empereur chrétien. Mais l'enthousiasme poétique n'est pas plus incompatible avec l'exposé d'une philosophie qui dénonce les mensonges de la mythologie qu'avec l'éloge d'un souverain dont la nouvelle foi condamne l'imposture des divinités païennes. Surtout, Optatien fait de Constantin son héros, comme Lucrèce l'avait fait d'Épicure. Pour Lucrèce, l'apologie de la poésie est inséparable de l'éloge d'Épicure : la relation entre le maître grec et le disciple latin est faite de mimétisme, un mimétisme fondé sur l'amour ${ }^{22}$. À la primauté d'Épicure dans le domaine de la pensée répond la primauté de Lucrèce dans son entreprise poétique. Il suffit de mettre en correspondance les termes : Épicure « osa pour la première fois » affronter la religion,

« son ardeur fut stimulée au point qu'il désira

forcer le premier les verrous de la nature.

Donc, la vigueur de son esprit triompha, et dehors

s'élança, bien loin des remparts enflammés du monde.

Il parcourut par la pensée l'univers infini. $»^{23}$

Lucrèce présente ainsi son projet poétique :

«Je n'ignore pas combien le sujet est obscur, mais d'un coup de son thyrse un grand espoir de gloire m'a violemment percé le cœur et mon âme se laissa pénétrer du doux amour des Muses ; ainsi frappé d'enthousiasme, l'esprit vaillant, des Piérides je parcours les lointaines contrées que nul n'explora. Joie d'aller aux sources vierges boire à longs traits, joie de cueillir des fleurs nouvelles, de glaner pour ma tête une couronne merveilleuse

dont jamais les Muses n'ont paré aucun front. ${ }^{24}$

Lucrèce s'élance sur des chemins poétiques que nul n'a foulés avant lui, pas plus qu'aucun homme ne s'était aventuré dans les sphères infinies parcourues par l'intelligence exceptionnelle d'Épicure: la métaphore spatiale est dans les deux cas exprimée par le même verbe, peragrare. De même, à la uiuida uis animi du philosophe répond la mens uigens du poète.

Les vers d'Optatien ne sont qu'un écho lointain et affaibli de ceux de Lucrèce, et pourtant l'analogie est réelle. Au «pouvoir remarquable» de Constantin répond 
l'« œuvre étonnante de l'esprit » qui consiste à «brocher le poème de vers qui suivent des parcours variés ». Les "chemins détournés » (deuia, v. 20)) sur lesquels les Muses encouragent le poète à s'engager désignent certes les vers qui traversent la page suivant des trajectoires autres que le sens ordinaire de lecture; mais ils s'appliquent aussi à l'ensemble de la démarche du poète, qui sort des sentiers battus en inventant un poème nouveau. Ce poème est un "don d'amour" (munus amoris, v. 34) du poète à l'empereur, et c'est à l'aune de la difficulté affrontée que se mesure cet amour. La relation du poète à l'empereur ne saurait pourtant s'exprimer sous la forme de l'imitation exaltée par Lucrèce : elle prend celle de la dévotion, qui permet à Optatien d'assimiler la composition du poème à l'accomplissement d'un vœu dont l'empereur est le destinataire. Cette dimension votive est essentielle pour comprendre la nature de la poésie porfyrienne. Elle permet d'intéresser l'empereur lui-même à la source divine de l'inspiration. Pour qu'un vœu s'accomplisse, il faut qu'il soit exaucé; tout le talent d'Optatien consiste à proclamer que son poème, accomplissement de ses vœux, est le signe visible de l'acquiescement de la sphère divine au pouvoir de Constantin. Un tel argument ne serait que spécieux s'il ne s'appuyait sur le fonctionnement des vœux dans le domaine politique.

La théologie qui sous-tend en effet l'éloge de Constantin par Optatien est le reflet fidèle de la théologie de la victoire en vigueur. La mystique impériale repose depuis toujours sur la victoire. Depuis les Antonins, la cause efficiente de la victoire est la uirtus de l'empereur, une uirtus qui a pris un caractère transcendant. Il s'agit d'une force surnaturelle qui ne symbolise plus l'effort humain, mais une énergie cosmique. L'autre composante du charisme impérial, la felicitas, après avoir eu la prééminence sur la uirtus en symbolisant la chance qui récompensait la piété du vainqueur, lui est désormais subordonnée, avec le sens nouveau de bonheur procuré par la uirtus à l'univers. C'est la felicitas saeculi ou felicitas temporum, par laquelle Commode rêva d'être l'auctor d'un nouvel âge d'or. À l'époque de Constantin, la conception de la victoire repose sur une doctrine " absolutiste » : dès lors que la victoire est attribuée au pouvoir surhumain incarné dans l'empereur, à cette uirtus qu'il doit à ses relations privilégiées avec la divinité, apparaît en effet le dogme de l'éternité et de l'ubiquité de la victoire impériale. Toutefois, pour bénéficier du soutien divin, l'empereur doit manifester sa pietas en rendant personnellement et en faisant rendre par ses sujets à la divinité le culte qui lui est dû. Ainsi, l'éternité du charisme impérial passe par des cycles renouvelés grâce à l'accomplissement d'un rituel, les vœux périodiques. C'est à ce renouvellement périodique qu'il faut rattacher la célébration des jubilés impériaux. Célébrés tous les dix ans depuis Auguste, ces anniversaires donnent lieu, depuis 157, à des émissions monétaires qui distinguent les uota soluta, correspondant à la période écoulée, et les uota suscepta, prononcés pour la période à venir. À partir de la même date apparaissent les uota uicennalia: on peut dès lors parler de fêtes jubilaires appelées Decennalia et Vicennalia. Sous la Tétrarchie, ces fêtes prennent de plus en plus d'importance, et leur contenu idéologique s'enrichit, notamment de la référence au mythe de l'âge d'or et à la mystique séculaire. Les Césars sont, à partir de Constance et de Galère, associés aux vœux prononcés, et les jubilés revêtent un caractère triomphal de plus en plus affirmé. Les Decennalia de Constantin en 315 furent l'occasion de célébrer à Rome, avec trois ans de retard, son triomphe sur Maxence. Retenu en 325 en Orient par le concile de Nicée, l'empereur fêta une première fois ses Vicennalia à Nicomédie, mais tint à rééditer la fête à Rome un an plus tard, pour lui donner toute la solennité requise et célébrer son triomphe sur Licinius. ${ }^{25}$ 
La majorité des poèmes porfyriens s'inscrit dans le cadre cérémoniel de la célébration de la victoire impériale ou des fêtes anniversaires du pouvoir. La circonstance est le plus souvent attestée par la présence d'une formule de vœux dans le poème. On relève ainsi plus de quarante occurrences de uotum dans les vingt poèmes constantiniens, auxquelles s'ajoutent les nombreux emplois de uouere et deuotus. La formule de vœux liée à l'anniversaire du natalis imperii clôt généralement le poème, lui conférant ainsi une solennité réelle et surtout une fonctionnalité qui renvoie directement au rituel collectif des vœux. L'offrande poétique d'Optatien prend ainsi sa place dans la liturgie jubilaire. L'exemple le plus flagrant de cette fonctionnalité est probablement celui des poèmes IV et $\mathrm{V}$. Le premier est un court texte de présentation du second : Optatien $\mathrm{y}$ précise le cadre cérémoniel dans lequel s'inscrivent ses poèmes, et commente la figure du poème $V$ :

Imperii fastus geminant uicennia signa,

pagina flexosa tramite uota notat.

Constantinigenis Helicon det talia natis

munera, deuotis haustibus ora rigans.

Hos rupes Cirrhaea sonet uideatque coruscos

Ponti nobilitas, altera Roma, duces.

Sed nunc te, uictor, uicennia picta honorent :

contentum tenui munere Musa cupit.

Quod textu scruposa siet mea pagina simplex,

disserat Augusto Calliopea mea.

«Les signes des Vicennales doublent les fastes de l'empire, ma page au chemin sinueux inscrit ses vœux. Que l'Hélicon accorde les mêmes présents aux fils de Constantin, baignant ma bouche de gorgées pleines de dévotion. Que l'antre de Cirrha fasse résonner leur éloge et que la noblesse du Pont, cette seconde Rome, voie ces chefs éclatants. Mais aujourd'hui, vainqueur, que les signes peints des vingt ans honorent ta personne : la Muse souhaite que tu sois content de ce modeste don. Que ma Calliope explique à Auguste combien ma page unique peine sous l'entrelacs. $»^{26}$

Les vers brochés du poème $\mathrm{V}$ dessinent de grandes majuscules qui reproduisent exactement une formule de vœux monétaire, associant les Decennalia des Césars et les Vicennalia de Constantin: AVG XX CAES X. Le texte composé par les lettres de ces mêmes vers brochés ajoute aux uota soluta de la légende monétaire des uota suscepta :

Cum sic scripta placent, audent sibi deuia Musae.

Per uarios signare modos deuotaque mentis.

Gaudia, quae pingens loquitur mea, Phoebe, Camena.

Summe parens, da uoce pia tricennia fari.

«Puisque de tels écrits plaisent, les Muses osent sortir des sentiers battus pour tracer les joies d'un esprit dévoué, que ma Camène exprime en les peignant, ô Phébus. Père très grand, accorde-moi de célébrer d'une voix pieuse les trente ans de règne. $»^{27}$

Pourtant la véritable prolifération du vœu dans la poésie porfyrienne ne peut en aucun cas être réduite à son expression politique. La parfaite conformité des poèmes IV et $\mathrm{V}$ au rituel officiel des vœux n'empêche pas le poète de faire venir ses vœux de l'Hélicon, en des "gorgées pleines de dévotion". Nous posions plus haut la question de la pertinence de la référence aux Muses et à Apollon dans cette poésie constantinienne. $\mathrm{Au}$ fil de nos détours par divers poèmes, se dessine une réponse propre au poète : la création poétique elle-même est engagée dans l'accomplissement du rituel par lequel est pérennisé le pouvoir impérial. Cet engagement repose sur la fonction votive des poèmes: ils participent, comme l'ensemble des vœux des sujets impériaux, au 
renouvellement du charisme impérial, en attestant la pietas de celui qui les compose. Il arrive que sur ce point Optatien s'en tienne à une orthodoxie politique telle qu'elle laisse imaginer un poème de commande. C'est le cas du poème VIII : le texte broché dessine le chrisme constantinien, assorti de l'inscription IESVS; le texte du poème justifie le principe d'une transmission dynastique du pouvoir en exaltant les figures de Constance et de Claude le Gothique, père et grand-père de Constantin, et en célébrant les Césars, ses fils. Or le début comme la fin du poème proposent une leçon politique très ferme sur l'éternité du pouvoir impérial. Aux premiers vers :

Accipe picta nouis elegis, lux aurea mundi,

clementis pia signa dei uotumque perenne.

Summe, faue. Te tota rogat plebs gaudia rite,

et meritam credit, cum seruat iussa timore

Augusto et fidei, Christi sub lege probata.

« Reçois, lumière d'or du monde, les signes pieux du dieu clément avec un vœu d'éternité, peints en vers élégiaques nouveaux. Très grand, sois-nous propice. Selon le rite, le peuple tout entier te demande la joie, et croit la mériter, puisque mis à l'épreuve sous la loi du Christ, il garde plein de crainte les préceptes d'Auguste et de la foi. ${ }^{28}$

répondent les derniers :

Ac tibi lege dei iussisque perennia fient

saecla pii sceptri te, Constantine, sereno.

«La loi et les commandements de Dieu, Constantin, feront durer éternellement ton règne pieux, dans la sérénité. $»^{29}$

On retrouve dans les mots du poète les composantes générales de la mystique du pouvoir impérial : la pietas de l'empereur et de ses sujets, manifestée périodiquement par des rites, lui assure le soutien divin et un pouvoir éternel. Mais dans le cas présent, Optatien reflète avec exactitude la doctrine constantinienne. Ch. Pietri a recherché les traits d'une «théologie du prince » dans un ensemble de textes « rédigés un peu avant le concile de Nicée, après la victoire sur Licinius, au moment où Constantin, maître de l' Orbis romanus, peut déclarer sans ambages à l'Orient quel sens il donne à sa victoire et quel usage il compte en faire $»^{30}$. Le dossier comporte quatre lettres de Constantin reproduites par Eusèbe dans le livre II de la Vita Constantini. Sans rentrer dans les détails de l'analyse, nous reprenons ici les conclusions qui sont éclairantes pour notre propos. Ch. Pietri a relevé que l'orchestration des thèmes dans ce dossier montre une parenté entre la propagande politique de 324 et celle de 313. Ainsi, le thème de l'avènement d'un temps nouveau « où la paix religieuse détermine la paix civile aussi sûrement que la persécution entraînait la guerre intérieure » apparaît dès 314, et trouve un développement remarquable dans la lettre adressée en 324 par Constantin aux Orientaux pour leur signifier sa foi chrétienne, leur rappeler les méfaits de la persécution menée par Dioclétien et leur promettre la paix religieuse :

" d'un côté, il place la guerre civile « déclenchée alors que toutes les affaires divines et humaines étaient en paix » (II, 49, 2), une tyrannie manipulée par la magie et la superstition (II, 50-51), le trouble cosmique créé par la persécution (II, 52) et finalement la faiblesse de ce système qui n'a point de descendance (II, 54). En contrepoint, le prince chrétien oppose la paix que fit régner son père, celui-là seul qui invoquait le Dieu sauveur (II, 49,1). Il rappelle son attitude à lui qui tout enfant a assisté au dérèglement du système (II, 51,1) et la paix qu'il a instaurée aussitôt en s'installant dans les commandements de Dieu (II, 55, 1). À plusieurs reprises, il invoque sa foi parce que celle-ci est le signe et la garantie de la concorde civile. (...) Constantin oppose sciemment à un système écroulé, dont Licinius est le dernier 
représentant, une dynastie qui apporte la paix, en s'établissant dès l'origine dans la

foi. » de Dieu, par le peuple des justes est la clé de la paix, de la concorde et donc du bonheur universel. Dans la lettre aux Orientaux, il tient un discours très révélateur de sa conception personnelle de la théologie de la victoire. Il est conscient que ses victoires ne sont acquises qu'au nom du Seigneur dont il porte le signe ; c'est pourquoi se mêlent en son âme l'amour et la crainte de Dieu : «Car j'aime sincèrement ton nom ; mais la puissance que tu as montrée par de multiples exemples, et par laquelle tu affermis ma

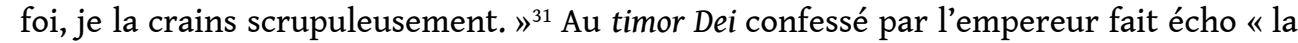
crainte » avec laquelle « le peuple observe les commandements d'Auguste et de la foi » dans le poème d'Optatien. ${ }^{32}$ Dans le même temps où il compose les lettres rassemblées au livre II de la Vita Constantini, l'empereur explique dans le Discours à l'assemblée des saints ce qu'il attend du peuple chrétien : «Par conséquent, tous ceux qui s'attachent à la piété doivent rendre grâce au Sauveur universel pour notre salut, le leur, et pour la prospérité de l'État, et nous rendre le Christ favorable par des prières saintes et des supplications continuelles, afin qu'il veuille bien faire durer éternellement ses bienfaits. $»^{33}$ Le poème VIII réalise poétiquement ce programme de pietas: Optatien offre à Constantin «les signes pieux du dieu clément avec un vœu d'éternité ». Le pouvoir éternel accordé par Dieu est celui d'une famille : l'éloge dynastique qui occupe l'essentiel du poème VIII consonne avec la condamnation par Constantin d'un système sans descendance dans la lettre aux Orientaux. Le système dynastique qu'il a rétabli est présenté comme le signe de l'élection divine, parce que cette nouvelle dynastie est fondée sur la foi.

Le poème VIII a été composé avant l'exil, sous le regard de Constantin. La profession de foi chrétienne qu'il contient est unique dans le corpus des poèmes. Le chrisme, présent dans deux autres poèmes, est ici clairement défini comme le nom du Christ, et assorti d'un bref énoncé doxologique qui précise la valeur confessionnelle du signe. Pour autant, Optatien confirme sa valeur prophylactique, en rappelant qu'il est le signe de Constantin, celui par lequel le Dieu des chrétiens lui donne la victoire. Le texte broché décline cette double valeur confessionnelle et prophylactique :

Alme, salutari nunc haec tibi pagina signo.

Scripta micat, resonans nominibus domini.

Nate deo, solus saluator, sancte, bonorum.

Tu deus es iusti, gratia tu fidei.

Sit Victoria comes Aug. et natis eius.

« Doux père, c'est pour toi que cette page écrite resplendit aujourd'hui

du signe salutaire, résonnant des noms du Seigneur.

Fils de Dieu, seul sauveur des hommes de bien,

Toi, saint, tu es le Dieu de la justice,

Tu es le don gracieux de la foi.

Que la Victoire accompagne Auguste et ses fils. »

L'unicité du poème VIII ne vaut pourtant que pour son degré de christianisation. Car le poème illustre d'une manière au contraire exemplaire pour l'ensemble du corpus la fonctionnalité d'une poésie destinée à prendre sa place dans la célébration rituelle du pouvoir. Simplement, l'orchestration des thèmes politiques et religieux dans le texte du poème et leur articulation avec le signe dessiné sur la page reflètent avec une telle conformité la doctrine constantinienne qu'on est amené à pressentir une influence très directe, sans doute sous la forme d'une commande, de l'empereur. Il est très frappant 
que le poème ne contienne qu'une allusion très vague à la forme : «les signes pieux du dieu clément... peints en vers élégiaques nouveaux». Hormis cette mention timide, la poésie s'efface totalement devant la gravité du message politique. Le poème VIII fonctionne à cet égard comme les poèmes XII et XIV, dont nous avons vu plus haut qu'ils participent à un programme de propagande constantinienne sur la justice et l'âge d'or. La parenté va plus loin encore. Aux poèmes XII et XIV nous avons opposé le poème III : dans les deux premiers cas, le message politique exclut le propos poétique, dans le second cas, l'apologie du poème instrumentalise à son profit un argument politique qui semble presque réduit à un prétexte. Que vaut, demandions-nous, ce "sceau» apollinien «marquant» l'âge d'or constantinien? Quelle réalité peut avoir pour l'empereur l'offrande de vœux exaucés par le dieu de la poésie ? Le poème VIII apparaît en effet comme l'exemple même de ce que peut attendre Constantin: une poésie totalement vouée à illustrer sa doctrine du prince chrétien. Pourtant, les poèmes dans lesquels l'univers mythique de la poésie est convoqué sont largement majoritaires, et certains d'entre eux font à n'en pas douter partie de l'envoi qui valut à Optatien son rappel d'exil. Or dans ces poèmes, l'engagement de la création poétique dans l'accomplissement du rituel politique est placé sous l'autorité du dieu de l'inspiration.

Loin de voir là une contradiction, il faut admettre que la présence des divinités de l'inspiration est justifiée par le rôle que leur attribue Optatien dans le rituel des vœux au cœur duquel il inscrit sa poésie. Le vœu poétique est la forme personnelle par laquelle Optatien participe au concert des vœux qui, conformément à la mystique du pouvoir impérial, contribuent à pérenniser ce dernier. Du poème VIII « christique » aux poèmes apolliniens, il ne doit pas y avoir aux yeux de Constantin solution de continuité. La même fonction votive, qui témoigne de la même loyauté à l'égard du pouvoir, prévaut dans l'un comme dans les autres. Toutefois, pour fonder son vœu poétique, Optatien met en place les éléments d'une mystique poétique qui puisse servir finalement à la mystique impériale. Pour commencer, en faisant prendre en charge la réalisation de son vœu par les divinités de l'inspiration, Optatien éloigne de sa pratique poétique particulière le soupçon de pure virtuosité technique étrangère à l'enthousiasme sacré. Le poème III montre que le vœu est étroitement associé à la difficulté du travail poétique : "Calliope... qui tisse difficilement... se réjouit si le dieu de Délos vient seconder ses vœux (si uota secundet / Delius)... Mais les filles de l'Aonie, confiantes en leur vœu (uoto / Aonides fretae), entraînent vers la joie un esprit qui t'est dévoué (tibi deuotam rapiunt ad gaudia mentem), et l'engagent à parler avec hardiesse en empruntant des chemins détournés ». Le travail sur la forme est le lieu où s'exerce la puissance du vœu: au lieu de minimiser la force de l'inspiration, il lui permet de se déployer. Tel est le sens des vers qui ouvrent le poème $\mathrm{X}$ :

Calliope cane plura procax. En ore serenus

fontis Castalii deus audiet ; inde canoros

mens furit in nexus, et felix currere uotis

iam se credet ouans. Libet ire per auia sola

impete quo gressus effandi optata cupido

inuitata tulit.

«Calliope, chante encore avec audace. Or voici que le dieu de la source de Castalie écoutera, le visage serein. Puis l'esprit se déchaîne en lacis mélodieux et, heureux de courir, se hasardera déjà à faire des vœux avec allégresse. Il aime aller par des lieux écartés et solitaires, dans un élan qui pousse son désir de proclamer ses souhaits à y porter ses pas. $»^{34}$ 

de phrases courtes, rythmées par des indications de temps où se mêlent, avec une confusion savamment organisée, l'impératif, le présent et le futur, qui livrent une sorte de chronologie de la furie poétique: d'abord l'invitation pressante faite à la Muse de chanter (Calliope cane plura procax), puis l'accord du dieu de l'inspiration, solennisé par le présentatif et un futur aux accents prophétiques (En ore serenus / fontis Castalii deus audiet), enfin, la véritable possession de l'esprit, le furor (inde... mens furit), qui s'exprime dans le choix formel d'une poésie unissant qualités musicales et qualités visuelles (canoros / mens furit in nexus), et qui a pour objet l'acclamation joyeuse des vœux (et felix currere uotis / iam se credet ouans). L'objet de la vaticination poétique ainsi mise en scène n'est autre que l'expression de vœux puisés à la source mythique. Les vers suivants décrivent cette furie prophétique. Le poète est mû par le « désir de proclamer ses souhaits " (effandi optata cupido) : effari est emprunté à la langue des augures, et optata est un équivalent de uota : fonction prophétique et fonction votive de la poésie sont ainsi associées. Or l'exutoire de ce désir prophétique et votif est la recherche impétueuse de chemins que nul n'a foulés. On songe une nouvelle fois à Lucrèce qui, "frappé d'enthousiasme ", parcourt des chemins non frayés; c'est le même adjectif, auia, qui est employé par Optatien, dont la joie fait écho à celle de son illustre prédécesseur. La métaphore spatiale de la course (v. 3-4) est prolongée par l'image de l'élan (impete) qui pousse le poète à porter ses pas sur de tels chemins (v. 4-5) : dans les deux cas, c'est le désir du poète de proclamer ses vœux qui entraîne le dynamisme de la création. La représentation de l'esprit inspiré courant les chemins de la création n'est pas sans pouvoir de suggestion. Il y a dans cette petite scène quelque chose qui relève de l'hypotypose, et par quoi la poésie visuelle, au lieu d'apparaître comme un exercice laborieux, dessine le «parcours » d'une inspiration qui s'offre aux regards: le texte broché, qui suit des chemins "écartés et solitaires ", se présente comme la matérialisation sur la page de la transe prophétique. Optatien peut alors affirmer à son lecteur impérial : "Mon esprit, très grand César, ne s'attache qu'aux nœuds de l'Aonie. » L'entrelacement des vers n'est pas un art technicien; il est de source divine, et ne saurait être mené à son terme sans une inspiration authentique : « Depuis le ciel resplendissant, répands rapidement, père, les Muses sur mon ébauche, en des vers qui répondent aux miens. » Depuis la première opération qui consiste à disposer sur la page les vers qui dessinent la figure jusqu'à celle par laquelle le poète entrelace ces vers et ceux qui vont constituer le texte "normal », tout s'accomplit sous le regard de Phébus.

39 La représentation de l'enthousiasme, dans le poème $\mathrm{X}$, sert à valider le vœu poétique. Un autre poème, le poème VII, illustre également la manière dont Optatien fait de la légitimité de son aspiration à être reconnu comme uates la condition de l'efficacité des vœux portés par le discours poétique. Dans la figure géométrique du poème, un octogone avec en son centre un petit carré, dont les angles sont reliés en diagonale aux angles du grand carré que constitue le poème lui-même, G. Polara a proposé de voir la représentation de deux lances croisées derrière un bouclier, c'est-à-dire d'un trophée. ${ }^{35}$ Nous avons surenchéri sur cette hypothèse en nous fondant sur le texte qui, célébrant Constantin comme le "modèle des Augustes » et le "modèle des vertus ", renvoie non seulement aux trophées constitués des dépouilles prises à l'ennemi et effectivement érigés pour célébrer la victoire, mais aussi au clipeus uirtutis, « bouclier de vertu » en or, offert par le Sénat à Auguste en 26 av. J.-C., « en hommage à sa vertu, sa clémence, sa 
justice et sa piété $»{ }^{36}$ Le panégyriste de 313 relate que l'Italie a dédié à Constantin, après sa victoire sur Maxence, une statue, un bouclier et une couronne en or : Debetur enim et semper debebitur et diuinitati tuae simulacrum aureum et uirtuti scutum et corona pietati. ${ }^{37}$ Le motif se retrouve sur la face nord de l'arc de Constantin: des Victoires inscrivent une formule de vœu sur le bouclier posé sur un pilier que flanque un captif. Le poème VII, qui décline les quatre vertus augustéennes incarnées par Constantin et proclame l'éternité de son charisme victorieux, affiche en lettres d'or sur la page une figure qui illustre, nous semble-t-il, la volonté de Constantin de s'identifier au modèle augustéen.

Or le texte du poème est rigoureusement structuré par l'orchestration des vœux. Aux vers 3 et 4, le poète place ses vœux sous l'autorité divine de Phébus :

Tu munera summa

uotorum da, Phoebe, mihi nunc, plena fauoris

« Toi, Phébus, accorde-moi à présent le don suprême des vœux, riche de ta faveur »,

mais ce don ne prend son véritable sens qu'aux vers 32 et 33, quand il se fond dans les vœux solennels que l'on acquitte au même moment dans tout l'empire romain :

En, accipe, clare

ductor, ubique tuis uotorum reddita, felix,

debita.

«Voici, reçois, illustre chef, les vœux dont partout l'on s'acquitte auprès de ta

famille, les vœux qui sont dus aux tiens, ô heureux Constantin ".

La fonctionnalité liturgique du poème découle de la volonté d'unir la voix individuelle du poète à la voix unanime des sujets impériaux, pour accomplir le rituel magique et religieux de renouvellement de cette énergie sacrée qui garantit la victoire, et dont les trophées, les clipei et les enseignes sont porteurs. Pourtant, le poème ne se réduit pas à l'offrande de vœux versifiés, si spectaculaires soient-ils. Toute la première moitié du texte s'intéresse une fois de plus au processus de l'inspiration :

Augustum specimen, mitis, magne

Ausonidum ductor, tua, maxime, fortia Musae

Castaliae de fonte canunt. Tu munera summa uotorum da, Phoebe, mihi nunc, plena fauoris, da mentem sensusque pios insigne serenus imperium, natisque potens, ad Martia felix, perpetuum saeclis, picto sub carmine fari. Audentem, precor, ipse iuua me, gloria uatum, dicturum carmen, quamuis nunc copia Musae non talis, possitque minus sub lege iuuari: uersu aliud limo, aliud, quo pagina in omnis signatur modulos, discernat semita fandi. Velle iubet numen, lux alma, et gaudia mundi instituunt; sequitur curas in musica uoto uirtutesque tuas et mores pandere gestit, sancte tuos. Creuit nostrae fiducia menti; te duce namque pio gaudens sub munere nota in iuga festinat Musis, ubi frondea semper texta canunt artes et notae uatibus undae.

"Modèle des Augustes, douce clémence, chef éminent des fils de l'Ausonie, les Muses, ô très grand, chantent tes actes valeureux, de la source de Castalie. Toi, Phébus, accorde-moi à présent le don suprême des vœux, riche de ta faveur, accorde-moi de chanter d'une voix sereine son intelligence, ses pieuses pensées, son pouvoir insigne, puissant grâce à ses fils et heureux dans les guerres, perpétuel pour les siècles, sous l'aspect d'un poème peint. Dans ce que j'ose, je t'en prie, aide- 
moi en personne, ô gloire des inspirés, au moment de chanter, quoique la Muse à présent n'ait plus même abondance, et que soumise à une telle loi, elle puisse moins être aidée : que mes paroles suivent deux sentiers, l'un fait de vers obliques, l'autre de vers tracés sur la page en suivant toutes les mesures. Ce dessein, la puissance des dieux l'ordonne, ô lumière bienfaisante, l'univers en liesse le fonde ; après les soucis vient la poésie, accomplissant mon vœu: elle brûle de dévoiler tes vertus et ton caractère, empereur vénéré. Dans notre esprit la confiance a grandi : car sous ton commandement, trouvant sa joie dans sa pieuse mission, il se hâte vers les cimes connues des Muses, où les toits couverts de feuillage et les eaux familières aux chantres inspirés chantent toujours les arts. $»^{38}$ Muses propre au genre épique, caractérisation purement topique des lieux de l'inspiration - Optatien construit une poétique du vœu. Elle passe encore par une chronologie de l'inspiration. Tu munera summa / uotorum da, Phoebe, mihi nunc : la prière est présentée comme contemporaine de l'énonciation du poème, et le présent (nunc) est celui de l'attente du poète, qui subordonne le discours poétique à l'expression de vœux directement inspirés par Phébus. Comme dans le poème $\mathrm{X}$, les temps verbaux rythment la résolution heureuse de cette attente. Le futur proche (dicturum carmen) entretient d'abord la fiction de l'attente de l'inspiration apollinienne; puis le présent salue l'accomplissement du vœu personnel du poète, c'est-à-dire le fait que les qualités proprement musicales du langage poétique viennent compléter l'élaboration d'abord visuelle de la figure : sequitur curas in musica uoto ( = musica sequitur curas in uoto). Enfin, le parfait prend acte de cet accomplissement (Creuit nostrae fiducia menti), qui détermine l'accès du poète au statut de uates: le présent de l'action en cours mime ce déplacement vers les lieux sacrés de la poésie inspirée (nota / in iuga festinat Musis), et l'évocation s'achève sur le présent intemporel dans lequel le poète comblé s'inscrit, puisqu'il fait désormais partie du cercle des poètes inspirés : ubi frondea semper / tecta canunt artes et notae uatibus undae.

Lorsqu'au v. 20, Optatien met fin à ces préliminaires et consacre la suite du poème à l'éloge exclusif de Constantin, il parle donc avec une autorité qu'il a fait advenir sous nos yeux dans le début du texte, celle du uates. Il est le chantre inspiré du bonheur universel garanti par la Victoire impériale; c'est à ce titre qu'il offre les vœux de l'empire à la famille constantinienne, des vœux inspirés par Apollon lui-même. Nous avons substitué plus haut à l'argument lucrétien d'une poésie épicurienne fondée sur l'imitation du maitre grec la revendication par Optatien d'une poésie constantinienne fondée sur la dévotion à l'égard de l'empereur ; pourtant ici, c'est bien d'une forme de mimétisme qu'il s'agit, sur laquelle repose ce que nous avons appelé la poétique du vœu. Car les deux parties du poème sont en étroite correspondance. L'objet du vœu dans la première partie est finalement le statut du poète : sa parole est sacralisée par le recours à la mystique de l'inspiration divine. Cette sacralisation dépend du soutien divin de Phébus, invoqué par le poète, et la réponse favorable à la prière de ce dernier est ainsi énoncée: Velle iubet numen (...) et gaudia mundi instituunt. La réussite du projet poétique est garantie par la volonté divine et fondée sur la joie universelle. La difficulté du travail poétique (curas) atteste la dévotion du poète, mais seule la puissance divine de Phébus transforme ce travail en un art des Muses qui peut se prévaloir de l'éternité (semper canunt). Dans la seconde partie du poème, l'objet des vœux rituels est le renouvellement du charisme impérial. C'est le statut du pouvoir impérial qui est en jeu, en l'occurrence son éternité confirmée par l'éternité et l'ubiquité de la victoire. À la volonté apollinienne exprimée plus haut répond ici le soutien de Dieu : 
Auctior alma dei per te praesentia mundum respexit, reddens mox aurea saecula rebus, ostenditque deus rectoris tempora iusti aetherio nutu placidis clementia iussis. Per te perque tuos sunt omnia mitia, uictor, natos, res populi florent ad gaudia mentis, Caesaribusque tuis toto Victoria in orbe semper iure comes felix in saecula pollet. Tantorum merita statues captiua tropaea, uictor Sarmatiae totiens. En, accipe, clare ductor, ubique tuis uotorum reddita, felix, debita. Iam compos gaudet tua, Romule, pubes: rector rite suus nobis per saecula floret.

«Plus forte grâce à toi, la présence bienfaisante de Dieu a tourné ses regards vers le monde, rendant bientôt son âge d'or à l'univers, et Dieu a fait paraître d'un signe céleste les temps cléments d'un maître juste au paisible commandement. Grâce à toi et à tes fils, ô victorieux, tout n'est que douceur, les affaires du peuple sont florissantes pour la joie de son cœur, et dans l'univers entier la Victoire, compagne à bon droit toujours propice de tes Césars, règne pour les siècles. De si grands exploits tu dresseras les trophées que tu as mérité de capturer, toi qui fus tant de fois le vainqueur des Sarmates. Reçois, illustre chef, les vœux qui sont dus aux tiens, ô heureux Constantin. Désormais exaucé ton peuple se réjouit, ô Romulus : son chef brille pour nous à juste titre pour les siècles. ${ }^{39}$

Le mouvement est quasiment le même que pour le vœu du poète : de même que celui-ci, aussitôt énoncé, a été exaucé par la puissance divine d'Apollon, les vœux publics sont d'ores et déjà réalisés grâce à l'assentiment divin au pouvoir impérial. Sous la forme du vœu, Optatien salue donc un double avènement: celui du verbe poétique et celui du pouvoir éternel de Constantin, le premier se mettant au service du second. La poétique du vœu consiste, par des effets de mimétisme, à couler la mystique de l'inspiration dans le moule de la mystique impériale. Un thème est à cet égard éclairant : celui de la joie. D'une apparente banalité, ce thème omniprésent dans la poésie porfyrienne figure dans les deux mouvements de notre texte: dans le premier, la joie du monde enseigne à vouloir chanter le pouvoir constantinien (Velle... gaudia mundi instituunt) et détermine, en même temps que l'injonction du dieu (Velle iubet numen), l'accomplissement du vœu poétique; dans le second, la joie du peuple romain découle de la douceur des temps sous le règne de Constantin et de ses fils (Per te perque tuos sunt omnia mitia, uictor / natos, res populi florent ad gaudia mentis) et de l'accomplissement des vœux publics en faveur de la famille impériale (Iam compos gaudet tua, Romule, pubes: / rector rite suus nobis per saecula floret). Cette notion de joie est si loin d'être anodine que, durant le règne de Constantin, pas moins de vingt-quatre séries de monnaies d'or la célèbrent, de 307 à 326 ; dix-neuf d'entre elles sont rattachées à un contexte militaire et commémorent les victoires remportées sur les Alamans, les Francs et les Sarmates. ${ }^{40}$ Ainsi, gaudium appartient tout autant que felicitas au registre victorieux, et se trouve à sa place dans un poème célébrant sans doute une victoire factuelle sur les Sarmates, mais surtout la victoire perpétuelle de l'Auguste. Tandis que felicitas est un principe actif d'origine divine, gaudium est le bénéfice pour les sujets de la felicitas que la divinité accorde à son élu. Cette joie, dans le poème VII, est au cœur du vœu poétique comme elle est au cœur des vœux publics. Dans les deux cas, elle témoigne de la felicitas constantinienne qui permet aux vœux de ses sujets d'être exaucés par le dieu. C'est assez dire que la mystique de l'inspiration est subordonnée à la mystique impériale. Constantin pouvaitil ne pas agréer une poésie dont la genèse répond à sa mystique du pouvoir ? Par la 
fiction d'un vœu poétique obéissant aux mêmes lois que les vœux de la sphère publique, Optatien fait de la réussite de son projet poétique un des effets du charisme victorieux de Constantin. Mais en même temps, l'univers mythique de la poésie garde son autonomie : il a sa propre divinité, qui prend en charge la réalisation du vœu du poète. Il y a ainsi une sorte de mise en abyme du vœu : l'objet du vœu exaucé par Phébus est en effet l'expression de vœux poétiques en l'honneur de l'empereur, en somme, une poésie porteuse de vœux. Par conséquent, en faisant de sa poésie l'objet d'un vœu adressé à Apollon, Optatien fait de la composition poétique qui en résulte une marque d'acquiescement de la divinité oraculaire au pouvoir du bénéficiaire des vœux, Constantin. C'est en ce sens que doit être comprise l'orchestration des vœux dans le poème VII.

C'est également ainsi qu'il faut comprendre le début du poème III par lequel nous avons commencé cette réflexion sur la démarche poétique d'Optatien. Rappelons que le poète se réclamait d'une double autorité, celle de Phébus, «qui donne de jouir de l'état de uates ", et celle de Constantin, qui "par les dons faits aux poèmes inspire l'esprit du poète ». Les vers suivants prennent désormais leur sens « fonctionnel»:

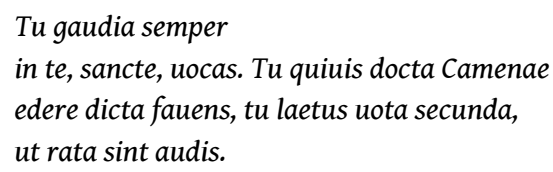

La poésie est au cœur de la joie dispensée au monde par l'empereur : elle est suscitée par cette joie, et elle en fait rejaillir les effets sur la personne impériale. Docta Camenae / edere dicta fauens, tu laetus uota secunda, / ut rata sint, audis: par la relation grammaticale fauens... audis se trouve suggérée l'identité des docta Camenae dicta et des uota secunda, en d'autres termes l'essence divine et prophétique des vœux par la médiation de la poésie. La courte subordonnée ut rata sint ne doit pas être oubliée : rata, qui revêt une double signification juridique et religieuse, renvoie à l'efficacité du rituel des vœux. Que l'on donne une valeur consécutive ou finale à la subordonnée, le sens reste le même: l'accomplissement des vœux est assuré de manière automatique, puisque la pietas de celui qui les formule est le reflet de la pietas par laquelle l'empereur bénéficie du soutien divin. Optatien invite Constantin à reconnaître dans sa poétique une mystique de l'inspiration parfaitement intégrée à la mystique du pouvoir impérial, cohérente avec ses aspirations absolutistes à un pouvoir éternel de droit divin et avec sa conviction que les prières de ses sujets contribuent à pérenniser son règne. Cette poétique repose sur la fonction votive des poèmes. Optatien renoue ainsi avec la lointaine tradition des technopaegnia alexandrins car, même si l'on ne peut préjuger de l'hypothèse selon laquelle les poèmes "à contour " grecs auraient eu comme support des objets votifs réels, leurs auteurs entretiennent du moins savamment cette fiction ${ }^{41}$. De cette fiction, Optatien fait une réalité ; sa page devient un objet votif, comme il l'affirme à la fin du poème III :

uix, arto in limite clausa,

nodosos uisus artis cata praeferat ex hoc,

et tamen ausa loqui tanto mens aestuat ore, nec dignum uotis carmen sic reddere retur, tali lege canens; quae nostrum pagina sola, ex Helicone licet, conplebit, munus amoris, picta elementorum uario per musica textu. ${ }^{42}$ 
Nous avons jusqu'ici, à l'image de notre poète, progressé per deuia. Mais c'est pour tisser, à sa manière, sur la chaîne du programme poétique qui se précise au fil des poèmes la trame du poème XIX. À bien des égards, ce dernier propose la forme accomplie du programme en question; il permet en particulier d'éclairer les termes de la convergence entre l'attente impériale et la "proposition » poétique d'Optatien que nous invoquions dans l'introduction à cette étude. Voici le texte du poème :

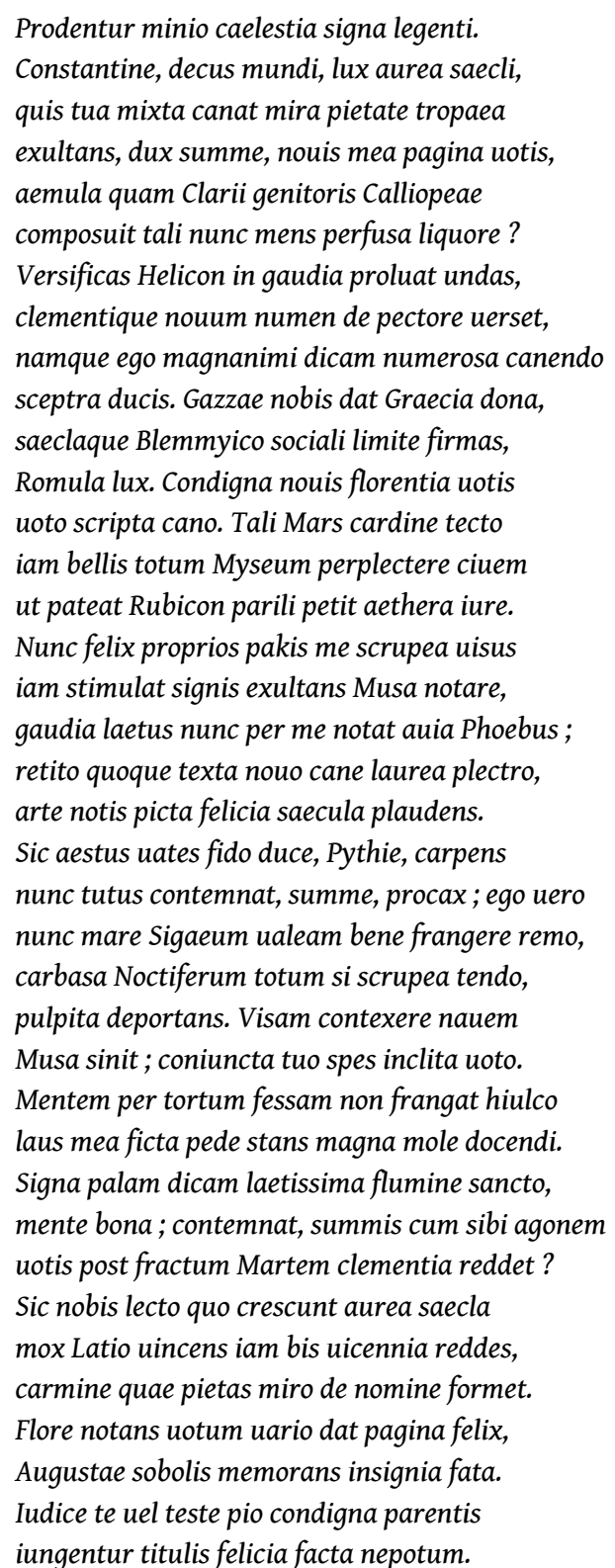

"L'encre rouge dévoilera au lecteur les signes célestes. Constantin, honneur du monde, lumière d'or du siècle, par quels vœux nouveaux ma page qui exulte pourrait-elle, chef suprême, chanter tes trophées mêlés à une merveilleuse piété, page émule du dieu de Claros qui engendra Calliope, page composée par un esprit à présent inondé d'une telle liqueur? Que l'Hélicon répande pour notre joie les eaux d'où naissent les poèmes, qu'il agite d'un cœur clément une nouvelle puissance, car je vais dire, en les rythmant par mon chant, les nombreux sceptres du chef magnanime. La Grèce nous donne les présents de Gaza, et tu fortifies notre siècle en faisant de la frontière des Blemmyes une frontière amie, lumière de Rome. Je chante des faits dignes de vœux nouveaux, des faits 
éclatants, écrits avec un vœu. Maintenant que cette extrémité est à l'abri, Mars gagne avec le même droit le ciel, pour qu'il soit désormais manifeste que le Rubicon punit par les combats tous les citoyens de la Mysie. À présent, ma Muse ardue, exultant de bonheur, me pousse à noter par des signes ses propres visions de paix, à présent, plein d'allégresse, Phébus trace par ma main des joies sans précédent; chante les lauriers tressés avec un plectre nouveau, fait lui aussi d'entrelacs, applaudis au bonheur des siècles avec un art brodé de lettres. Puisse ton poète inspiré, Pythien, gagnant les flots bouillonnants sous ta conduite assurée, en sûreté à présent, les braver hardiment à ce prix; quant à moi, j'aurais bien la force, à présent, de rompre à la rame la mer Sigéenne, si je déploie les voiles ardues, faisant avancer mes planches tout le temps où brille l'étoile du soir. La Muse me laisse tisser le navire dont j'ai eu la vision ; à ton vœu est unie une espérance illustre. Que mon éloge, composé en respectant la mesure, avec une grande masse d'enseignements, n'aille pas abattre à cause d'un hiatus mon esprit fatigué par les détours. Je divulguerai en un flot sacré les signes très heureux, d'un cœur propice : la clémence les tiendrait-elle pour négligeables, quand, la guerre une fois brisée, elle rivalisera avec les vœux les plus grands qui lui avaient été adressés ? Ainsi, toi dont l'élection fait croître pour nous les siècles d'or, bientôt tu t'acquitteras pour la deuxième fois, en vainqueur dans le Latium, de tes vingt ans de règne, auxquels ma piété donne forme en un poème, à partir d'un nom admirable. La page féconde offre son vœu en le traçant avec des ornements variés, rappelant les remarquables destinées de la descendance d'Auguste. Les heureux faits de tes descendants, tout à faits dignes de toi, juge ou témoin affectueux, s'ajouteront aux titres de leur parent. »

Le texte broché est le suivant :

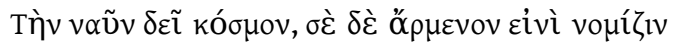

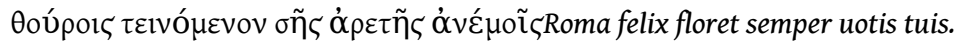

Nauita nunc tutus contemnat, summe, procellas.

Nigras nunc tutus contemnat, summe, procellas.

Tutus contemnat summis cumulata tropaeis.

Pulsa mente mala contemnat, summe, procellas.

Spe quoque Roma bona contemnat, summe, procellas.

« Il convient d'interpréter le navire comme représentant l'univers,

et le gréement comme te représentant, tendu par les vents impétueux de ta valeur.

Rome, heureuse, fleurit toujours des vœux en ton honneur.

Que le marin, dorénavant en sûreté, brave, ô très grand les orages.

Qu'en sûreté dorénavant, il brave, ô très grand, les noirs orages.

Qu'il brave en sûreté les flots grossis par les puissants vents de terre.

L'esprit du mal chassé, qu'il brave, ô très grand les orages.

Que Rome aussi, pleine d'un bon espoir, brave, ô très grand, les orages. »

Le poème XIX est d'abord conforme aux leçons des poèmes précédents. La poétique du vœu y est plus que jamais revendiquée par son auteur qui, comme dans les exemples précédemment étudiés, fait de l'inspiration poétique une manifestation de la joie universelle. Tel est le sens des premiers vers :

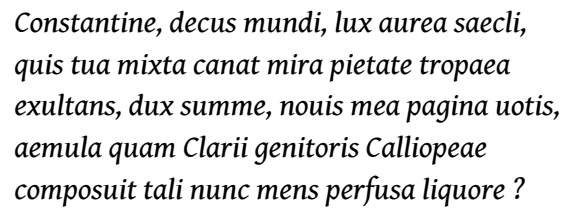

La question est révélatrice de la valeur programmatique de l'énoncé : il s'agit, une fois encore, de célébrer par un chant puisé aux sources mythiques de l'inspiration la victoire acquise par l'empereur grâce à sa piété. Elle est non moins révélatrice de la 
difficulté pour le poète de se renouveler : "par quels vœux nouveaux...? ?. Derrière la flatterie convenue, point une vraie question. Optatien, tout au long de ses précédents poèmes, a pris soin d'inscrire sa poésie dans le cadre de la mystique impériale; en la ritualisant de la sorte, en lui assignant une fonctionnalité qui revient à scander les slogans de la propagande impériale, il assume la part de répétitivité inhérente à cette tâche. Pourtant, les vers qui suivent immédiatement, loin d'afficher le doute, adoptent la solennité de la célébration épique :

Versificas Helicon in gaudia proluat undas,

clementique nouum numen de pectore uerset,

namque ego magnanimi dicam numerosa canendo

sceptra ducis.

Suit, à travers les exemples de Gaza, ville de Palestine, et des Blemmyes, peuple du haut Nil, un bref éloge de la reconquête de l'Orient par Constantin. Optatien conclut alors avec assurance :

Condigna nouis florentia uotis

uoto scripta cano.

L'énoncé quelque peu laborieux de cette déclaration amène à soupçonner une difficulté liée à la réalisation de la figure. De fait, le vers 12 correspond au sommet de l'inscription VOT sur la figure; plus précisément, le mot votis dessine la barre supérieure du $\mathrm{T}$ et appartient de ce fait au texte broché qui dessine l'inscription: «Rome, heureuse, fleurit toujours des vœux en ton honneur. » La remarque n'est pas anodine, car la coïncidence entre le texte et la figure vient à propos pour éclairer l'assurance du poète. Les vers 12-13 sont en effet la réponse à la question qu'il posait plus haut: c'est par la forme figurée de sa poésie qu'Optatien peut chanter les hauts faits de son héros en se renouvelant.

La figure du poème XIX justifie cette prétention : aucune autre n'atteint le degré de complexité de celle-ci, dont le tracé échappe à la raideur géométrique jusqu'à donner une impression de délié dans le corps du navire, proue, poupe et gouvernail, tout en permettant des effets combinatoires grâce à ce qu'il conserve de géométrique, une coque constituée de deux droites reliées entre elles par des diagonales qui s'entrecroisent en se prolongeant dans les rames. La figure combine en outre un effet de réel dans le dessin de la forme du navire et la valeur symbolique du signe à travers la figuration du mât et des vergues par un chrisme et de la voile par l'inscription VOT. Un autre aspect original est la pluralité de sens portés par la combinaison du texte et de l'image. Discours politique et discours poétique sont savamment entrelacés, mais Optatien mêle en outre, dans l'un comme dans l'autre, voix officielle et voix personnelle. Le navire est la figure unificatrice de tous ces sens, et agit à la fois comme image, symbole, et métaphore.

Si l'on s'en tient à la figure, l'ordonnance de ses éléments tout comme le commentaire qu'en offre le texte broché se rapportent à un sens purement politico-religieux, au demeurant d'une cohérence remarquablement efficace. En effet, la représentation du navire est à elle seule un condensé de la théologie de la victoire ; tous les éléments de la figure sont signifiants et correspondent aux éléments constitutifs du charisme impérial. L'identification du navire à l'univers et de l'empereur aux agrès, ainsi que l'affirmation que les marins embarqués n'ont plus à craindre les orages, soulignent la qualité salvatrice et providentielle du pouvoir constantinien. Les vents qui poussent le navire sont le souffle de l'Arétè de Constantin, l'équivalent grec le plus courant de 
Virtus, principe transcendant du pouvoir impérial qui s'apparente à une énergie cosmique. Cette "valeur » est fondée sur l'élection et le soutien divins grâce au signe salutaire qui garantit la victoire constantinienne, le chrisme tenant lieu de mât avec sa vergue. Optatien n'a garde d'oublier que la protection divine dont dépend le bonheur universel passe par la fidélité des sujets de l'empire à la fois à Dieu et à l'empereur : voilà pourquoi les vœux constituent la voile, fixés au chrisme-mât et indispensables à la marche du navire. Le signe $\mathrm{XX}$ annonce enfin qu'est venu le moment du renouvellement périodique de cette force surnaturelle à travers la célébration des Vicennales. On est même tenté de donner un sens à la distinction entre vers grecs et vers latins dans le texte broché : les vers grecs renvoient en effet au sens purement symbolique, théologique, de la figure, dont ils fournissent l'exégèse, tandis que les vers latins, introduits par la formule votive inscrite dans les grandes lettres VOT (« Rome, heureuse, fleurit toujours des vœux en ton honneur »), illustrent la fonction liturgique du poème en formulant les vœux en question, qui résonnent comme l'actualisation du symbole à travers la célébration de la circonstance. La répétition de nunc souligne cette actualisation, tandis que l'allusion à « l'esprit du mal chassé » rappelle la circonstance, à savoir la victoire récente sur Licinius, adversaire de Dieu et persécuteur des chrétiens.

Or un souvenir poétique nous semble se mêler à cette composition politique. Le « marin désormais en sûreté » (nauita nunc tutus) fait écho au " marin craintif » (timidus nauita) d'Horace dans l'ode 14 du premier livre des Odes. Quelle que soit la signification réelle du poème, Quintilien en faisait l'exemple de l'allégorie comprise comme une suite continue de métaphores et l'interprétait ainsi : « le navire représente l'État, les flots et les tempêtes les guerres civiles, le port la paix et la concorde.» À l'avertissement d'Horace qui décourageait le navire de l'État de prendre la mer, parce qu'il était trop délabré pour affronter les intempéries, s'oppose le chant victorieux d'Optatien, qui scande avec allégresse dans les cinq vers brochés multipliés par la combinatoire la nouvelle sécurité de l'État, qui brave les orages. Pour exprimer la fragilité du navire, Horace passait en revue son gréement: rames arrachées, mât brisé, antennes gémissantes, quille privée de câbles, voiles déchirées. La métaphore du navire appartient depuis longtemps au registre politique, et elle a toujours été utilisée pour justifier un type de gouvernement particulier, le gouvernement unique d'un homme providentiel, depuis le kubernètès de Platon, qui est au-dessus des lois, jusqu'à l'empereur élu par la divinité, en passant par le consul pourvu du summum imperium ex senatus consulto de Cicéron. ${ }^{43}$ Mais dans la métaphore traditionnelle, l'État est le navire et son chef en est le pilote. Optatien modifie donc sensiblement les termes de la métaphore en faisant de Constantin non pas le gubernator, mais le gréement du navire. Outre le sens symbolique d'une telle représentation, par laquelle le cours de l'univers et la carrière impériale sont intrinsèquement liés, il y a comme une réponse directe à Horace. Les agrès du navire font désormais sa solidité et sa force: Rome et avec elle l'univers entier sont désormais pourvus d'un chef éternel au destin duquel le leur s'identifie. Il n'est pas impossible que le souvenir d'Horace ait contribué au renouvellement de la métaphore.

La leçon politique du navire comme symbole du bon gouvernement du monde par un chef unique et providentiel élu par Dieu est entièrement explicitée par la figure et le texte broché. Le texte du poème propose toutefois, sous une forme allusive, deux autres lectures. Les vers 35 et 36 permettent d'imaginer un motif factuel pour le choix du navire : la page, « avec ses ornements variés », dit le poète, "rappelle les remarquables destinées de la descendance d'Auguste ». Dans la phase ultime du conflit avec Licinius, 
Crispus, le fils aîné de Constantin, a joué un rôle de premier plan en anéantissant la flotte de l'ennemi près d'Andrinople, empêchant de ce fait le ravitaillement de Byzance assiégée par Constantin. ${ }^{44}$ Le navire renvoie donc implicitement à cette victoire navale. D'autre part, aux vers 10 et 11, le poète cite le motif d'éloge suivant: «La Grèce nous donne les présents de Gaza, et tu fortifies notre siècle en faisant de la frontière des Blemmyes une frontière amie, lumière de Rome ». Nous avons vu plus haut que cet éloge est immédiatement suivi d'une déclaration qui renvoie par la mention du vœu à la figure du poème, donc au navire. Gaza, ville côtière de Palestine, a été développée et agrandie par Constantin; elle était le point de départ des marchandises étrangères venues des provinces orientales et acheminées dans les provinces de l'empire par les navires grecs. ${ }^{45}$ Le navire pourrait figurer ici le problème vital du ravitaillement : grâce à la reconquête de la partie orientale de l'empire par Constantin, le bonheur matériel de Rome est assuré par un bon approvisionnement. Plus largement, c'est l'oeuvre de pacification aux confins orientaux de l'empire qu'Optatien souligne en mentionnant les Blemmyes ; Eusèbe les cite dans la Vita Constantini pour montrer l'extension de l'empire sous Constantin "jusqu'aux extrêmes limites méridionales ", et les fait figurer dans la revue des légations barbares qui se pressaient aux portes du palais pour offrir à l'empereur des dons en signe d'obéissance et d'alliance. ${ }^{46}$ Le navire symboliserait ainsi la force commerciale et politique de Rome en Orient.

On ne doit pas exclure non plus que le navire d'Optatien soit un symbole de Felicitas. Si cette composante du charisme impérial n'est pas présente dans le commentaire grec de la figure, les vœux (VOT) qui dessinent la voile mettent en scène Roma felix. Le poème entier exalte le bonheur dispensé par l'empereur, à l'image de ces vers euphoriques : Nunc felix proprios pakis me scrupea uisus / iam stimulat signis exultans Musa notare, / gaudia laetus nunc per me notat auia Phoebus; / retito quoque texta nouo cane laurea plectro, / arte notis picta felicia saecula plaudens. Et le poète déclare plus loin vouloir dévoiler des signa laetissima qui désignent certainement la figure du poème. Or le lien entre le navire et la Felicitas est établi par les représentations monétaires depuis Hadrien. ${ }^{47}$ Sur les monnaies de ce dernier, le navire est représenté en mouvement, la voile gonflée par le vent, avec des rangs de rameurs et un pilote. Sur la voile est inscrite la légende Felicitati Aug. ${ }^{48}$ Cette représentation monétaire peut être mise en rapport avec les nombreux voyages d'Hadrien dans les lointaines provinces de l'empire, voyages destinés à montrer aux populations l'intérêt personnel que prend l'empereur à leur prospérité. On retrouve la représentation d'un navire, accompagnée de la même légende, sur des monnaies du principat de Marc-Aurèle et de Lucius Vérus. ${ }^{49}$ Dans le cas de ce dernier, le lien peut encore être établi avec une navigation réelle, ${ }^{50}$ mais il ne l'est plus pour MarcAurèle. Il ne l'est pas davantage pour le jeune Commode, en l'honneur duquel sont frappés des as portant la légende Felicitati Caes.$^{51}$ Le bateau est devenu le symbole de la Felicitas apportée par les empereurs durant leurs pérégrinations, et par leur seule présence. En 186, Commode fait représenter un navire naviguant avec des rameurs, accompagné de la légende Prouid Aug. ${ }^{52}$ Le sens de la représentation du navire est désormais clairement établi : il symbolise le bonheur que l'empereur, désigné par les dieux, répand sur le monde entier. Sous son gouvernement, Rome connaît l'espoir d'une paix éternelle et exerce sa domination sur le monde.

Le lien entre la navire et la Félicité publique ne se dément pas pendant la période troublée que connaît Rome au $\mathrm{III}^{\mathrm{e}}$ siècle : on retrouve le navire impérial comme symbole de la Felicitas temp(orum) sur des monnaies d'Élagabal et de Postumus. Il est lié au thème de l'âge d'or. ${ }^{53}$ Avec Constantin cependant, on se trouve devant une étrange difficulté : 
le navire figure bien sur plusieurs de ses monnaies, mais toutes les émissions sont postérieures au poème d'Optatien. Un premier groupe de monnaies célèbre la victoire de Constantin sur Licinius. Le navire apparait ainsi sur un médaillon de bronze frappé à Rome dans les années 327-333. ${ }^{54}$ L'avers représente un buste avec le casque lauré, le manteau impérial et le sceptre, et porte la légende Constantinopolis. Sur le revers figure le navire se dirigeant vers la droite, avec le capitaine en face de cinq rameurs, trois enseignes à la poupe et, à la proue, la Victoire tenant une couronne. Sous le navire, l'artiste a représenté une mer agitée ; la légende est Victoria Aug. Le navire célèbre la défaite navale de Licinius. Sur un autre type frappé à Constantinople en 327-328, la Victoire est représentée debout au milieu du navire, brandissant une couronne dans chaque main. ${ }^{55}$ Elle domine largement par sa taille le navire dont on devine la poupe, la proue, le gouvernail et les rames. La légende est Libertas Publica. Au début de 327, quatre nouveaux types de monnaies de bronze furent créés à Constantinople par Constantin pour célébrer sa victoire sur Licinius, ajoutant quatre notions propres à formuler un message politique cohérent: Gloria Exercitus, Gloria Romanorum, Libertas Publica et Spes Publica. ${ }^{56}$ Que tirer de ces émissions monétaires qui intéresse notre réflexion? D'une part, Optatien n'a pas pu s'inspirer de types monétaires qui sont postérieurs à son poème; pour autant, la longévité du type du navire symbole de Felicitas en fait une source d'inspiration possible dans le registre figuratif. D'autre part, les émissions significatives de monnaies avec représentation du navire pour célébrer la victoire constantinienne sur Licinius attestent a posteriori l'accueil favorable que le navire d'Optatien, célébrant cette même victoire, dut recevoir. Il faut admettre que le poète a anticipé brillamment la propagande impériale..$^{57}$

61 Le navire du poème XIX n'est pourtant pas seulement celui du pouvoir. Le passage central du texte nous convie en effet à y voir aussi le navire de la poésie :
Nunc felix proprios pakis me scrupea uisus
iam stimulat signis exultans Musa notare,
gaudia laetus nunc per me notat auia Phoebus;
retito quoque texta nouo cane laurea plectro,
arte notis picta felicia saecula plaudens.
Sic aestus uates fido duce, Pythie, carpens
nunc tutus contemnat, summe, procax; ego uero
nunc mare Sigaeum ualeam bene frangere remo,
carbasa Noctiferum totum si scrupea tendo,
pulpita deportans. Visam contexere nauem
Musa sinit ; coniuncta tuo spes inclita uoto.

La création poétique est sous le signe de la Felicitas et, à défaut du navire du pouvoir, c'est le navire de la poésie que l'on voit braver les flots bouillonnants sous ses auspices, avec pour pilote le dieu Phébus. Le tissage des vers qui dessinent la figure et des vers du poème permet au poète de tisser étroitement le discours politique et le discours poétique : les mots nunc tutus contemnat s'appliquent à la fois au marin embarqué sur le navire constantinien de la figure et au poète embarqué sur le navire pythien de la poésie dans le texte. Si l'on s'en tient à la définition donnée par Quintilien, Optatien propose ici une nouvelle allégorie: le navire, seulement suggéré par l'image aestus carpere, représente cette fois le poème, les flots agités la difficulté de la création poétique ; le marin-poète est guidé par le pilote sûr qu'est le dieu de l'inspiration. Le registre métaphorique concerne ici l'écriture, assimilée à la traversée d'une mer houleuse. Les vers suivants substituent à la désignation générique du poète (uates) une première personne qui semble s'en distinguer: ego uero. L'anaphore de nunc, qui 
consonne en outre avec le nunc des vœux exprimés dans le texte broché, relie cependant étroitement les deux énoncés. Dans ce nouveau registre métaphorique, la mer a un nom, la mer Sigéenne, le marin est le poète locuteur ; le navire, désigné par la métonymie pulpita, est caractérisé par ses "voiles ardues", carbasa scrupea. L'adjectif scrupea est familier au lecteur des poèmes porfyriens : appliqué soit à la Muse dans le poème présent (v. 16-17), soit aux poèmes eux-mêmes (scrupea carmina, X, 9), soit encore au mode d'expression choisi par Optatien (per scrupea fari, III, 27), il sert toujours à exprimer la difficulté de la poésie figurée. Le navire représente donc dans le cas présent la poésie figurée, plus précisément le poème figuré que nous avons sous les yeux, comme le confirme le vers suivant : «La Muse me laisse tisser le navire dont j'ai eu la vision ». Du reste, Optatien évoque ce navire sous la forme précise des éléments qui composent la figure du poème XIX : rames, planches, voiles. Une chose est donc sûre: Optatien embarque métaphoriquement sur le navire qu'il a tissé et le fait naviguer.

Mais là s'arrête la certitude. Car plusieurs interprétations sont ensuite possibles. G. Polara a interprété ces vers comme le souhait d'optatien que son poème traverse la mer jusqu'à l'empereur. L'ignorance dans laquelle nous sommes du lieu de l'exil d'Optatien et l'impossibilité de trancher sur le sens de Sigaeum ne permettent pas de préciser davantage cette hypothèse. Elle semble néanmoins plausible. Le souhait d'une traversée réelle par laquelle le poème parviendrait à son destinataire n'est d'ailleurs pas contradictoire avec le sens métaphorique de la navigation. La métaphore maritime est ainsi utilisée par Quintilien pour désigner l'acte de publier ses livres. À Tryphon qui le sollicite, il répond : «Chaque jour, avec une insistance grondeuse, tu m'as demandé de commencer enfin à publier les livres relatifs à la formation de l'orateur, que j'ai rédigés à l'intention de mon ami Marcellus. Personnellement, je ne les croyais pas assez mûrs. (...) Pourtant, si cette publication est demandée avec autant d'insistance que tu l'affirmes, livrons les voiles au vent, et, au moment de larguer les amarres, formons pour eux des vœux fervents. $\aleph^{58}$ La publication est un acte par lequel l'œuvre échappe au contrôle de son auteur, et entame une carrière aventureuse, au même titre qu'un voyage maritime. L'image de la navigation est propre à traduire l'inquiétude de l'auteur et son incertitude face à la réception réservée à son œuvre. Elle convient donc parfaitement à la situation d'Optatien, poète en disgrâce. Pourtant, l'utilisation de la première personne et par conséquent le sentiment, cohérent avec les termes de la métaphore filée, que le poète est embarqué, nous amènent à voir dans ces vers plus qu'un simple désir de voir le poème parvenir à Constantin. Ce n'est pas seulement à son poème qu'Optatien souhaite faire traverser la mer, mais à lui-même. Dans le poème qui sert de préface aux poèmes envoyés à Constantin, le poète dépêche en suppliante à la cour de l'empereur une Thalie qui personnifie son recueil, et lui-même s'efface totalement derrière cette intercession. L'image de la navigation est ici plus complexe : marin qui fait avancer son navire, le poète identifie son sort à celui de son poème. S'il mène à bon port son navire, il pourrait bien franchir la mer qui le tient en exil ; en d'autres termes, s'il réussit le travail poétique particulièrement ardu que représente la composition de ce poème, il pourrait bien être rappelé par Constantin. Le souhait n'est pas exprimé directement, mais il est présent sous le voile de la métaphore. Derrière le navire figuré, derrière le navire métaphorique, c'est un navire réel, celui du retour d'exil, qu'Optatien appelle de ses vœux. On peut comprendre en ce sens les vers suivants : 
Mentem per tortum fessam non frangat hiulco

laus mea ficta pede stans magna mole docendi.

Signa palam dicam laetissima flumine sancto,

mente bona ; contemnat, summis cum sibi agonem

uotis post fractum Martem clementia reddet?

64 imposée, au v. 30, par la figure, d'où le caractère contourné de l'énoncé. Néanmoins, le sens logique de l'ensemble est assez clair : Optatien revient sur la réalisation du poème, qui respecte les règles métriques tout en proposant une figure très élaborée et riche de sens. C'est le poème entier, mais avant tout la figure dessinée sur la page, qu'il désigne par les termes de signa laetissima, et il souligne l'excellence de ses intentions dans cette offrande poétique : dans ces conditions, lorsque l'empereur fera succéder la clémence aux rigueurs de la guerre afin d'exaucer les vœux de ses sujets, si grands soient-ils, comment ne pas espérer qu'il exaucera le vœu le plus grand de son poète, être rappelé d'exil?

Compte tenu de la complexité de la figure, de la pluralité des sens, le poème XIX présente un niveau de cohérence assez exceptionnel. Trois voix investissent le texte: celle du laudateur, celle du poète, celle enfin, discrète mais audible, de l'exilé. Si le navire du pouvoir se dessine seul sur la page, le langage métaphorique suscite dans le texte des images de la navigation du poème. L'une fonctionne selon le mimétisme que nous avons déjà relevé entre la mystique de l'inspiration et la mystique du pouvoir impérial. Le uates, en effet, «brave en sûreté les tempêtes » sous la conduite de Phébus, au même titre que les sujets de l'empire sous la conduite de Constantin. La Félicité des temps rejaillit sur la création poétique, la transformant en une navigation sûre. Par la juxtaposition de la navigation politique et de la navigation poétique à travers le tissage des vers, le charisme poétique atteste et célèbre le charisme impérial, comme en témoignent ces vers : retito quoque texta nouo cane laurea plectro, / arte notis picta felicia saecula plaudens. L'autre image de la navigation du poème met en scène le poiètès, tant il est vrai que les gestes de la navigation (mare... ualeam bene frangere remo, / carbasa... si scrupea tendo, / pulpita deportans) semblent décrire le travail de composition de la figure. Si le poète inspiré parcourt hardiment les flots, le poète fabricant de son texte est à la tâche pour manœuvrer le navire. Or si l'exilé peut espérer être gracié, c'est autant pour la dévotion personnelle dont témoigne son difficile travail de poiètès que pour la caution divine que, comme uates, il invoque dans la réalisation de son vœu.

Il reste à mettre en lumière un dernier aspect propre au poème XIX. Nous avons vu précédemment que Phébus et le Christ s'excluent mutuellement : dans les poèmes VIII et XIV, dont la figure est constituée par le chrisme, Phébus et les Muses sont absents. Dans le poème III, le motif de la croix, si l'hypothèse est juste, cohabite certes avec un poème entièrement dédié à Phébus et aux Muses. Mais il n'est explicitement question que du «visage » de Constantin, et la figure n'est pas commentée. Seul le poème XVI célèbre à la fois le Christ dans des acrostiches écrits en lettres grecques et Phébus dans le texte du poème. Or dans le poème XIX, Optatien dresse le chrisme sur le navire, le commente dans le texte broché et dans le poème, en même temps qu'il consacre la plus grande partie du texte à célébrer l'inspiration poétique, son dieu et ses Muses. Voilà posée une dernière fois la question de la pertinence de cette célébration dans une poésie constantinienne, question à laquelle nos détours par d'autres poèmes ont apporté les premiers éléments de réponse. La mystique de l'inspiration dont se réclame Optatien revêt la même fonctionnalité presque mécanique que la mystique du pouvoir 
impérial : à travers une poétique du vœu, la parole poétique se rattache au rituel de renouvellement du pouvoir éternel de l'empereur. Elle puise cependant son efficacité à ses propres sources mythiques. Le poème XIX joue complaisamment du thème de la source des Muses : tali nunc mens perfusa liquore (v. 6), Versificas Helicon in gaudia proluat undas (v. 7), Signa palam dicam laetissima flumine sancto (v. 29. Cette eau qui inonde la poésie n'est pas étrangère aux flots bouillonnants que le navire-poème traverse, et pourrait relever d'une variation synonymique propre au poème XIX. Mais la palme triomphale figurée par le poème IX est aussi présentée comme l'offrande par la Muse des «palmes qu'arrose et nourrit l'eau qui coule dans le val des filles d'Aonie ». Le topos de l'eau de l'inspiration a pour fonction de rappeler l'origine, la source surnaturelle du discours poétique. Était-elle crédible aux yeux de Constantin?

Il est regrettable qu'on ne puisse faire fond sur l'authenticité des lettres placées par la tradition manuscrite en tête du recueil de poèmes, et attribuées l'une à Porfyrius, l'autre à Constantin. ${ }^{59}$ Les Muses y ont leur place. A Constantin, Porfyrius s'adresse en ces termes, pour le remercier de l'accueil favorable qu'il a réservé à un premier poème :

«Que devrais-je faire, moi qui ne possède qu'un maigre talent, dont le mérite jusqu'à présent était tout petit? L'autorité de ton jugement céleste a conféré un poids immense au témoignage d'un empereur qui, entre ses qualités guerrières et pacifiques, entre les triomphes et les lauriers, entre les sanctions des lois et les droits, applaudit encore les Muses qui lui sont familières, de sorte qu'entre tant de distinctions de ta divine majesté par lesquelles tu es toujours invincible et premier, de ce goût aussi l'éclat remarquable étincelle en toi. (...) Si, comme les sages en ont décidé, très grand empereur, les jugements doivent être estimés pour leur valeur et non pour leur nombre, moi qui ai obtenu un témoignage de cette nature par l'autorité céleste de ton affection, il m'est désormais permis de gagner tranquillement les sommets du Parnasse et d'oser même en sûreté faire descendre les Muses des hauteurs sacrées de l'Aonie, quels que soient les chemins que mon esprit prend dans les poèmes ${ }^{60}$. $»$

Constantin, dans sa lettre, commence par rassurer le poète qui a dû protester que sa Muse était légère ; si l'on ne recherchait que la gravité, l'éloquence grecque se serait tue après le poète de Chios ou celui de Méonie, l'éloquence latine après celui de Mantoue. Mais, ajoute-t-il, les siècles suivants ont su reconnaître l'œuvre de ceux qui ont incliné les rythmes vers plus de légèreté.

«La grâce de l'éloge convoité a rejailli sur chacun en proportion de l'harmonie de son chant. Mais au talent de certains a manqué la faveur des temps, qui a coutume d'irriguer et de nourrir les esprits adonnés à la science à la manière du ruisseau qui, descendu du sommet d'un chemin escarpé, tempère de ses veines débordantes la sécheresse des champs. Mon écoute bienveillante accompagne comme une douce brise ceux qui écrivent et parlent dans mon siècle; enfin, je ne refuse pas non plus aux études le témoignage qu'elles méritent. Les discours ont toujours eu un libre cours ; mais ceux qui s'expriment en vers, la loi imposée aux mètres les a contenus dans des limites strictes : c'est pourquoi l'usage a légitimement imaginé que ceux qui veulent s'exprimer de cette manière gagnent les lieux sacrés de l'Hélicon ou du Parnasse, puisque le secours divin apparaît nécessaire quand les ressources du talent humain font défaut ${ }^{61}$.»

69 L'empereur poursuit en louant l'art d'Optatien qui a su, tout en respectant les règles anciennes de la poésie, en créer de nouvelles. Après une brève description de son procédé visuel, il conclut en ces termes :

«Par conséquent, ce présent de ta dévotion m'a été agréable : l'exercice auquel se livre ton esprit et ta facilité naturelle ont reçu mon entière approbation. De ton côté, puisque tu vois que la faveur que tu avais demandée à mes oreilles pour ton 
œuvre n'a pas disparu, tu devras et te réjouir du succès présent, et chercher à

obtenir des éloges mérités par l'exercice de ton talent. » production littéraire et la référence à l'inspiration poétique. Sur ces deux points, ce qui pourrait passer pour un éloge convenu dans la lettre de Porfyrius, prend dans la lettre de Constantin l'allure d'un manifeste. L'empereur exprime d'abord sa volonté de soutenir la production littéraire, à travers les images du ruisseau qui irrigue les champs et de la brise légère. La première comparaison commente de manière générale la nécessité d'un temporum fauor, sans lequel le talent des auteurs, qui a besoin de la laudis gratia, ne peut se développer; la seconde concerne le benignus auditus dont Constantin, dans une phrase programmatique, entend faire le fondement de sa politique culturelle. L'empereur commente ensuite l'«usage " qui consiste à dire que ceux qui vont s'exprimer dans le genre poétique "gagnent les lieux sacrés de l'Hélicon ou du Parnasse ». Ce commentaire reprend directement l'image utilisée dans la lettre de Porfyrius pour désigner l'activité poétique que lui permet la faveur impériale. La justification invoquée par Constantin est intéressante : l'usage de la référence aux lieux sacrés (sacra) de l'inspiration n'est pas illégitime, cum mortalis ingenii deficiente substantia necessaria uiderentur auxilia diuina. Constantin affirme clairement ici que l'image traditionnelle de l'inspiration poétique est justifiée par une réalité: l'aide divine apportée au talent humain. Les termes employés ne sont pas moins intéressants que l'idée : Constantin ne nomme pas directement l'inspiration, mais en décrit les effets à travers la périphrase diuina auxilia. Cette périphrase renvoie à une expérience personnelle de l'empereur, invoquée tout au long de ses lettres et discours comme le fondement même de son règne : celle du secours que la divinité lui apporte par sa puissance, et dont le signe est le chrisme qu'il a fait dessiner sur les boucliers et les enseignes de ses soldats. Dans une lettre adressée durant l'hiver 324-325 au roi de Perse Sapor, Constantin développe les thèmes qui traduisent son expérience religieuse et fondent sa foi : grâce à la lumière de la vérité, il reconnaît le vrai Dieu ; avec l'aide de sa puissance, il s'est soumis l'empire en commençant par les frontières de l'Océan; son armée porte sur ses épaules le signe sacré du Dieu qu'il vénère, et il est récompensé par de magnifiques victoires ${ }^{62}$ Constantin cite comme preuves de la Providence de Dieu les bienfaits innombrables dont jouissent ceux qui lui rendent le culte qui lui est dû et, $a$ contrario, la fin misérable dans laquelle sa colère a précipité les persécuteurs. L'« aide divine » est donc au cœur de l'expérience religieuse de Constantin, et ne peut être de sa part une formulation anodine. Au contraire, il faut admettre qu'il se plaît à transposer cette expérience dans d'autres registres que le registre politique, en l'occurrence ici le registre poétique.

On pourrait objecter que l'authenticité de la lettre de Constantin à Porfyrius est douteuse. Mais si l'auteur n'est pas Constantin, il est en tout cas un fin connaisseur de la pensée constantinienne. Car sa défense de l'inspiration poétique est cohérente avec un texte qui a, lui aussi, posé des problèmes d'attribution, mais dans lequel on s'accorde aujourd'hui à reconnaître un écrit authentiquement constantinien. Le Discours à l'assemblée des saints fut très probablement prononcé par l'empereur à Antioche, devant les membres d'un synode réuni à l'occasion de la fête de Pâques, et après la défaite de Licinius, soit en avril $325 .{ }^{63} \mathrm{Il}$ reflète les "préoccupations littéraires, philosophiques, religieuses, mais aussi politiques $»^{64}$ de Constantin, au moment où il vient de reconquérir la partie orientale de l'empire. Comme la lettre aux Orientaux et comme la lettre au roi de Perse, le Discours, dans lequel l'auteur entend faire une démonstration 
de l'existence de Dieu et de la nécessité de pratiquer la foi chrétienne, développe le thème de la Providence divine qui prodigue ses bienfaits à ceux qui observent les lois divines, tandis qu'un châtiment terrible s'abat sur les persécuteurs de l'Église. Constantin lui-même exprime sa reconnaissance au Dieu dont la bienveillance lui a permis de triompher de ses rivaux. Cette réflexion s'assortit d'une critique du paganisme et de ses représentants les plus illustres, tels que les philosophes et les poètes. À propos de ces derniers, Constantin adopte une position qui est proche de celle de Lactance. Lorsque les poètes représentent les dieux soumis aux passions humaines ( $\dot{\alpha} v \theta \rho \omega \pi 0 \pi \alpha \theta \varepsilon \tilde{\tau} \varsigma)$, en racontant leurs combats et leurs blessures, leurs joies et leurs gémissements, il faut les juger dignes de foi : «Si en effet ils recherchent le talent

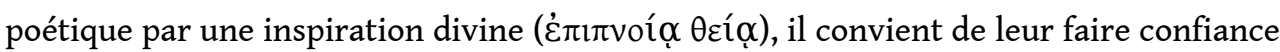
et de les croire au sujet de ce qu'ils disent en étant inspirés par la divinité ( $\pi \varepsilon \rho \grave{\omega} \tilde{\omega} v$

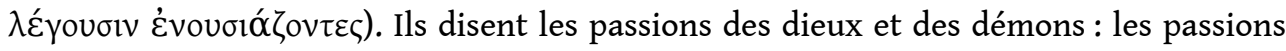
de ceux-ci ont donc reflété la vérité sous diverses formes. " ${ }^{65}$ Comme Lactance dans les Institutions divines, Constantin renverse l'argument par lequel les défenseurs de la religion païenne attribuaient à la licence poétique les anthropomorphismes discréditant l'image de la divinité. ${ }^{66} \mathrm{Au}$ contraire, dit Constantin, en montrant les dieux du paganisme soumis à des passions trop humaines, les poètes disent la vérité, à savoir qu'ils ne sont que des hommes divinisés. À cette vérité poétique reposant sur l'inspiration divine, Constantin oppose le mensonge intéressé des poètes, lorsqu'ils sont mus par l'appât du gain ou la crainte d'un danger : « Mais, dira-t-on, il est permis aux poètes de mentir : en effet, charmer les âmes de ceux qui écoutent est le propre du talent poétique, tandis que la vérité, c'est lorsque l'objet du discours n'est pas différent du discours. Admettons que ce soit le propre de la poésie d'arracher la vérité ; mais ceux qui disent des mensonges ne mentent pas en vain : en effet, soit ils mentent en vue d'un gain ou d'un avantage, soit, ayant conscience de quelque mauvaise action, ils la voilent à cause du danger dont les lois les menacent ; car ils auraient pu, à mon avis, sans rien rapporter sur la nature divine qui aille contre la vérité, éviter le mensonge et l'impiété. » ${ }^{67}$

72 On a souvent interprété ces lignes comme une condamnation pure et simple de la fiction poétique. Leur affinité avec les idées défendues par Lactance sur la poésie nous incline au contraire à les lire comme une tentative de récupérer l'inspiration poétique afin de la faire servir à la cause de la vérité chrétienne. ${ }^{68}$ La preuve en est qu'après avoir opposé dans les chapitres suivants aux erreurs et aux mensonges du paganisme les témoignages de la vraie religion, Constantin entreprend de convaincre les païens par leurs propres témoignages. Il commence par évoquer la Sibylle d'Érythrée: elle prétendait avoir vécu à la sixième génération après le déluge, et fut préposée par la stupidité de ses parents au service d'Apollon, d'où il ne ressortait rien de convenable ni de saint, mais seulement des désirs inconvenants, si l'on en croit ce qu'on raconte sur le dieu et Daphné - Daphné à laquelle était consacré un sanctuaire fameux dans les faubourgs d'Antioche. "Eh bien", poursuit Constantin, "ce fut elle qui, un jour, entraînée à l'intérieur du sanctuaire par une crainte superstitieuse inopportune, et

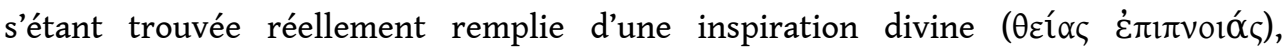
prophétisa en vers ce qui allait arriver concernant Dieu, montrant clairement par la disposition des premières lettres, qu'on appelle acrostiche, l'histoire de la venue de

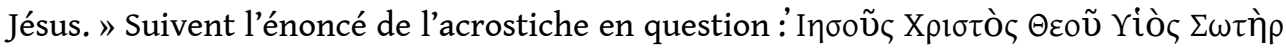
$\Sigma \tau \alpha u \rho o ̀ \varsigma$, puis le poème de trente-quatre vers. Constantin conclut alors : «Et cela, de toute évidence, arriva à cette vierge de la part de Dieu en vue d'une prédiction; je la 
juge donc bienheureuse, celle que le Sauveur a choisie comme prophétesse de sa prévenance envers nous. ${ }^{69}$ Dans le chapitre suivant, Constantin défend le poème acrostiche contre ceux qui, tout en reconnaissant dans la Sibylle une prophétesse, voient dans ce texte un faux créé par « quelqu'un de notre religion, non dénué de l'art poétique des Muses. » Il prétend s'appuyer sur une traduction latine qu'en aurait faite Cicéron, mais déforme en réalité un passage dans lequel Cicéron mentionne le fait que les Livres Sibyllins à Rome étaient composés en acrostiches, preuve à ses yeux que ces vers n'étaient pas d'inspiration divine, car l'acrostiche suppose un auteur contrôlant parfaitement son écriture. ${ }^{70}$

73 À ce témoignage de la Sibylle succède... Virgile, «le plus éminent des poètes de l'Italie ». Constantin propose une lecture chrétienne de la quatrième Églogue. L'interprétation du texte virgilien dans le sens d'un prophétisme chrétien est présente à la fois dans le commentaire des vers par l'auteur du Discours et dans la traduction grecque du poème virgilien, traduction manipulée de manière à mieux exprimer la valeur prophétique présumée, c'est-à-dire l'annonce de la naissance du Christ. ${ }^{71}$ Constantin se livre à une véritable exégèse de la quatrième Églogue, suivant le postulat que les choses y sont dites «à la fois de manière visible et de manière cachée à travers l'allégorie : en effet, ceux qui examinent à fond la puissance des paroles ont sous les yeux la divinité du Christ ; mais afin d'éviter qu'un des chefs de la cité impériale puisse accuser le poète d'écrire contre les lois de la patrie et de rejeter les usages ancestraux au sujet des dieux, il voile la vérité. $\gg^{72}$ Le mot n'est pas prononcé, mais on retrouve ici l'une des raisons du mensonge poétique énoncées au chapitre 10, la peur des lois en vigueur. Plus loin, Constantin adresse à Virgile ce satisfecit : «Bien dit, poète très sage. $\mathrm{Tu}$ as étendu la liberté poétique jusqu'à la limite convenable. Tu n'avais pas pour but de rendre un oracle, puisque tu n'étais pas prophète; et tu en étais aussi empêché par le danger qui menace ceux qui rejettent les usages consacrés par les ancêtres. ${1^{73}}^{3}$

Les analyses de Constantin traduisent indéniablement une influence de Lactance : la théorie évhémériste selon laquelle les poètes transmettent à travers leurs mythes une vérité historique, la conception positive de la licentia poetica qui en découle, l'intérêt pour les Oracles Sibyllins considérés comme des diuina testimonia qui proclament le vrai Dieu et annoncent l'avènement du Fils de Dieu, ${ }^{74}$ la conviction enfin que la quatrième Églogue, même si elle est l'œuvre d'un très grand poète, ressortit aux Carmina sibyllina, portent dans le Discours à l'assemblée des saints la marque de celui que Constantin, après l'avoir côtoyé dans ses jeunes années à Nicomédie, avait fait venir à Trèves pour y être le précepteur de son fils Crispus. Tous ces thèmes sont largement développés dans les Institutions divines. Mais Constantin s'en empare d'une manière doublement personnelle: d'une part, il affirme ainsi sa volonté d'exercer une autorité dans le domaine culturel; d'autre part, il relie dans un champ d'expérience commun l'ensemble de ses préoccupations religieuses, politiques et littéraires. Il est en effet très frappant de constater que la même expression désigne l'inspiration divine dans des domaines a priori distincts. Au seuil de son Discours, conscient de la grandeur et de la difficulté de sa tâche, l'empereur demande l'aide de l'inspiration divine : «Que la très

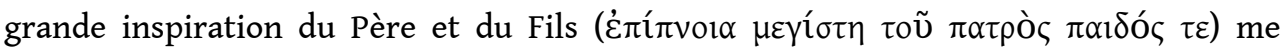
vienne en aide dans ma tâche, moi qui dis ce qu'elle veut bien me faire comprendre et me confier. En effet, chaque fois que quelqu'un qui étudiait la rhétorique ou toute autre science pensait pouvoir mener à bien son ouvrage sans l'aide de Dieu, on le voyait échouer, ainsi que ce à quoi il s'appliquait; au contraire, ceux à qui il advient d'obtenir l'inspiration divine ne doivent ni hésiter ni se montrer négligents. $»^{75} \mathrm{~A}$ la fin du même 
discours, Constantin passe en revue les tyrans persécuteurs châtiés par Dieu: Dèce, Valérien, Aurélien, Dioclétien, Licinius enfin, le seul à n'être pas nommé, tous ont été détruits. Dieu a répondu aux prières des opprimés, et leurs louanges et actions de grâces saluent la défaite du mal et le retour de la liberté et de la justice: "Cela ne prouve-t-il pas en tout point la Providence de Dieu et son amour pour les hommes?» Dans le dernier chapitre, l'empereur évoque enfin sa situation personnelle : « Lorsqu'ils louent mon service ( Dieu ( $\dot{\varepsilon} \xi \dot{\varepsilon} \pi ı \pi v o i ́ \alpha \varsigma \theta \varepsilon o \tilde{)})$, n'affirment-ils pas bien haut que Dieu est l'auteur de mon courage ? Certainement. Le propre de Dieu est en effet d'agir pour le mieux, le propre des hommes est de lui obéir. " ${ }^{76}$ L'action du prince, son "service» (ن் particulièrement ses guerres, sont inspirées par Dieu. Cette inspiration, affirme Constantin, vient en réponse à sa foi et à ses prières, et lui garantit la victoire, parce qu'il agit pour le bien des hommes.

75 L'utilisation du même vocable pour désigner sa propre expérience de l'inspiration divine, dans ses paroles comme dans ses actes, et l'inspiration de la Sibylle et des poètes, est révélatrice de la mentalité religieuse de Constantin. Elle permet de comprendre pourquoi, au lendemain d'une victoire qui le rend maître d'un empire réunifié et devant un public d'évêques, il juge bon de livrer son sentiment sur la foi que l'on peut accorder aux poètes et de poser les prémisses de l'interprétation chrétienne d'un grand poète profane. Que Lactance ait fourni la matière de cette interprétation ne retire rien au fait fondamental que Constantin a foi dans l'inspiration divine. Son expérience personnelle l'a convaincu de la réalité de ce secours apporté par Dieu à l'homme, et il transpose sans difficulté cette expérience dans d'autres domaines. Pour le lecteur du Discours à l'assemblée des saints, l'authenticité constantinienne des propos adressés à Porfyrius sur l'inspiration poétique, conçue comme une "aide divine », est très plausible. Certes, dans le Discours, il n'est question ni des Muses, ni d'Apollon, mais seulement de Dieu, ou du dieu. Mais, comme le dit Constantin en conclusion du Discours, «c'est le propre de Dieu de faire les meilleures choses, c'est le propre des hommes de lui obéir » : cette maxime lui permet d'être sensible à l'argument du poète qui invoque l'inspiration divine afin de surmonter les difficultés de sa tâche. Lui-même n'en fait-il pas autant au moment de prononcer son discours? S'en remettre à la puissance divine rend capable de grandes et belles choses : voilà une conviction qu'il peut partager avec son poète.

76 La pratique directe de l'acrostiche par Optatien dans quelques poèmes, et le fait que ses figures apparaissent d'une certaine manière comme de géniaux avatars de cette pratique, amènent à faire un autre rapprochement avec le Discours à l'assemblée des saints. Constantin y montre son intérêt, sans doute suscité par Lactance, pour un poème acrostiche qu'il présente comme un Oracle Sibyllin. On imagine dès lors que, sans confondre les genres, il ait eu plaisir à retrouver un peu du prestige de cette littérature dans les offrandes poétiques d'Optatien. Dans le poème XIX particulièrement, les lettres qui dessinent le chrisme et le gouvernail composent un distique grec. Optatien avait déjà eu recours à ce tissage des langues latine et grecque dans le poème XVI. L'acrostiche composait une adresse en latin à l'empereur: "À notre Seigneur Constantin Perpétuel Auguste », et trois mésostiches célébraient en hexamètres grecs le pouvoir constantinien: "Seigneur, le Christ t'a accordé, ainsi qu'à tes fils, comme récompense de ta piété et pour prix de ta vertu, d'exercer le pouvoir, d'inaugurer une bonne législation, et de régner sur les Ausoniens ». Constantin, semble-t-il, n'était alors 
maître que de la partie occidentale de l'empire. Les vers brochés grecs du poème XIX, s'ils ne nomment pas le Christ, sont inscrits dans son monogramme et, comme les vers grecs du poème XVI, ils célèbrent le pouvoir constantinien fondé sur la vertu, un pouvoir désormais étendu à tout l'univers. Le recours au grec dans ces deux cas est-il significatif? Il attire en tout cas l'attention sur un énoncé destiné à fonder le pouvoir constantinien sur cette Providence divine qui, aux dires mêmes de l'empereur, anime et récompense sa vertu. Le grec est la langue des Oracles Sibyllins. J. Svenbro, dans l'ouvrage qu'il a consacré avec J. Scheid au mythe du tissage dans le monde grécoromain, propose une lecture originale de ces oracles. En 125 av. J.-C., des présages effrayants se multiplièrent en Italie, et le Sénat demanda aux décemvirs de consulter les oracles de la Sibylle. La technique selon laquelle ces derniers composèrent la réponse, en partant d'un ou plusieurs hexamètres peut-être tirés au sort dans les Livres Sibyllins, s'apparente au tissage: "Le "tissage» de la Sibylle et des Dix tisserands s'avère donc avoir une implication technique précise: il signifie l'union entre l'hexamètre sélectionné, figé et inaltérable, et la séquence des vers qui vont en être générés en vue d'une situation de crise. Il signifie l'entrelacement de l'énoncé " dur ", traditionnel, et de son exégèse souple et attentive au présent. Mais, sur un plan plus général, ce tissu ou histos possède également une autre signification; constitué de mots grecs, il prescrit des rites qui vont être accomplis «à la grecque » (Akhaïsti) par des Romains, à Rome. Il est la rencontre de deux cultures, un lieu de croisements, un lieu où d'entrelacent des réalités opposées jusque dans le sens de leurs fibres. ${ }^{77} \mathrm{Si}$ l'on transpose cette méthode d'explication dans le cas particulier des poèmes porfyriens, l'union d'un texte latin et d'un texte grec préfigure, dans le poème XVI, et salue, dans le poème XIX, l'unification de l'empire. Dans un tissu qui entremêle les fils de la réalité latine et de la langue grecque, l'énoncé solennel du soutien du Christ à Constantin résonne comme un appel à reconnaître l'universalité d'un pouvoir providentiel. Que cet énoncé soit grec alors que les lettres qui le composent appartiennent à un texte latin a quelque chose de magique : c'est « le même qui s'unit à l'autre ». Par les fils de chaîne grecs mêlés à la trame latine, serait annoncée et célébrée la reprise en main par Constantin de la partie orientale de l'empire, le tissu de lettres symbolisant la réparation de l'unité déchirée.

Quoi qu'il en soit de sa parenté avec les Oracles Sibyllins, le poème XIX, plus que tout autre dans le corpus des poèmes constantiniens, invoque la puissance oraculaire du dieu de l'inspiration. Il est désigné comme le "dieu de Claros", sanctuaire très renommé pour sa mantique, il est appelé "Pythien». Certes, Optatien se contente du pouvoir de suggestion des épithètes, mais il est presque aussi discret dans ses allusions au Christ. Aux vers 25-26, il déclare : «La Muse me laisse tisser le navire dont j'ai eu la vision; à ton vœu est unie une espérance illustre. » La référence à la figure permet de comprendre ainsi la deuxième partie de la déclaration : aux lettres VOT qui dessinent la voile (tuo uoto) est uni le chrisme, signe du Christ qui apporte l'espérance du salut (spes inclita). De même, le « nom admirable » (v. 34) à partir duquel la piété du poète « donne forme " par un poème aux vingt ans de règne constantinien désigne sans doute les lettres du monogramme XP(istos). La clarté du sens de la figure contraste avec la relative discrétion du texte. Or cette figure est présentée avec insistance comme une vision, un signe divin. Le premier vers proclame déjà : «L'encre rouge dévoilera au lecteur les signes célestes» (caelestia signa); la Muse pousse le poète à «noter par des signes ses propres visions de paix » (proprios pakis... uisus / ... signis... notare) ; elle le laisse tisser « la vision d'un navire » (Visam... nauem) ; enfin, le poète divulgue les « signes très 
heureux» (Signa... laetissima). C'est une poésie «visionnaire» qu'Optatien offre à Constantin, et par là il concilie l'inspiration apollinienne et le soutien du Christ. Car la vision, comme l'inspiration, s'inscrit dans l'expérience constantinienne. La vision poétique du navire avec chrisme réédite la vision inaugurale du signe victorieux à la veille de la bataille contre Maxence. Mais on ne doit pas oublier que cette vision n'est pas la première qu'ait proposée la propagande impériale. Le panégyriste de 310 s'était fait l'écho d'une première vision apollinienne: Apollon, accompagné de la Victoire, était apparu à Constantin à Grand, pour lui offrir des couronnes de laurier annonçant trente années de règne. ${ }^{78}$ Cet épisode fut effacé par l'invention du chrisme, signe constantinien par excellence, mais il vient à propos pour rappeler l'attachement de Constantin à Apollon avant sa conversion au christianisme. C'est l'Apollon solaire qui fut d'abord son comes, et si la référence à la divinité s'effaça évidemment à mesure que s'affirmait la nouvelle foi de Constantin, la mystique solaire subsista. On s'accorde à reconnaître que le Soleil, sous une forme neutralisée, « désinfectée » de son sens cultuel païen, continue à éclairer la gloire de Constantin. ${ }^{79}$ Rappelons qu'Optatien, dans le poème XII, invoque encore directement le Soleil, « descendance invaincue du maître du tonnerre ", comme soutien de l'empereur. Il n'est pas exclu que le poème $\mathrm{X}$ offre à Constantin une vision de sa gloire solaire. Composé avant l'exil, il propose à la vue une figure dessinée en lettres d'or sur un fond pourpre; dans son poème de préface, Optatien évoque le « rayonnement intérieur » de ses écrits (radiantibus intus scriptis) : or la figure du poème $\mathrm{X}$ rayonne littéralement à partir des deux grandes diagonales qui coupent le poème. L'éclat qui se diffuse sur les quatre côtés de la page à partir de son centre matérialise la lumière que le texte met au cœur de l'éloge dynastique de la famille constantinienne. ${ }^{80} \mathrm{Et}$ le dernier vers du poème invite l'empereur à contempler cette vision lumineuse : Aspice : pacato parta est lux laeta sub orbe.

Ainsi Phébus et le Christ peuvent-ils ne pas paraitre inconciliables aux yeux de l'empereur, dans une poésie qui se plie si bien à sa propre représentation de l'origine surnaturelle de son pouvoir. Optatien a su convertir de manière fonctionnelle la mystique de l'inspiration poétique à la mystique impériale, et la religiosité syncrétiste de Constantin pouvait s'accommoder à un double titre de la référence à Phébus et aux Muses: d'une part, le crédit qu'il accorde à l'inspiration poétique dans le Discours à l'assemblée des saints le disposait à accepter un culte des Muses tout à sa dévotion, d'autre part, Phébus pouvait encore jouir, sous une forme poétique " neutralisée ", du prestige du dieu solaire. La poésie d'Optatien est encore loin de l'alternative à laquelle se trouveront confrontés les poètes chrétiens. Que l'on songe aux mots adressés par Paulin de Nole à son maître Ausone pour exprimer le renversement des valeurs qu'entraîne sa conversion à la vie parfaite : " Pourquoi me conseilles-tu, mon père, de m'occuper encore des Muses que j'ai reniées? Ils se refusent aux Camènes, ils ne sont pas ouverts à Apollon, les cœurs voués au Christ. $»^{81}$ Le christianisme de pure commande auquel semble adhérer Optatien n'explique pas seul sa poésie de conciliation. Elle est également cohérente avec la préoccupation de Constantin de préserver un équilibre entre ses convictions chrétiennes et les croyances païennes d'un grand nombre de ses sujets. À cet égard, la poésie d'Optatien reflète une période de transition, au point d'être apparue elle-même à bien des regards critiques comme une poésie de transition, trop peu païenne et trop peu chrétienne pour qu'on la crédite d'une inspiration authentique. Or le poème XIX, par la richesse et la consonance des thèmes religieux, politiques et poétiques qu'il propose autour de la figure du navire, est l'aboutissement d'un art poétique qui a consciemment converti le jeu virtuose en un 
projet réfléchi, soucieux de célébrer, à travers la grandeur impériale, la grandeur de la poésie et la force de l'inspiration.

\section{NOTES}

1. G. Polara, Publilii Optatiani Porfyrii carmina, I : Textus, adiecto indice uerborum ; II : Commentarium criticum et exegeticum, Torino, Paravia, 1973. Nous citons le texte latin de cette édition; nouvelle édition : Carmi di Publilio Optaziano Porfirio, a cura di G. Polara, Torino, Utet, 2004 (trad. annotée).

2. Hier. Chronica, ed. R. Helm, Eusebius, VII, 232 : Porfyrius misso ad Constantinum insigni uolumine exilio liberatur.

3. Fort. Carmina, V, 6, 11 : inter haec illud me commouens, quod tale non solum feceram, sed nec exemplo simili trahente ducebar. Cf. Venance Fortunat, Poèmes, t. 2, texte établi et traduit par M. Reydellet, Paris, Belles Lettres, 1998, note 91 p. 171: "Cette affirmation implique que cette pièce est antérieure aux carmina figurata du livre II, et, d'autre part, que Fortunat ne connaissait pas les œuvres de Porphyrius Optatianus. Sur ce second point, on peut douter de sa sincérité. Peut-être veut-il dire que son projet d'un poème de trente-trois vers de trente-trois lettres chacun est, en tant que tel, original. "

4. Bed. De arte metr. $(G L 7,258)$ : reperiuntur quaedam et in insigni illo uolumine Porphyrii poetae, quo ad Constantinum Augustum misso meruit de exilio liberari; quae quia pagana erant, nos tangere non libuit.

5. Raban Maur, MGH.Ep. 5, 2, 383 : Porfyrius..., secundum cuius exemplar litteras spargere didici.

6. Cf. U. Ernst, Carmen figuratum. Geschichte des Figurengedichts von den antiken Ursprüngen bis zum Ausgang des Mittelalters, Köln Weimar Wien, 1991, p. 54-94 ; M.-O. Bruhat, Les carmina figurata de Publilius Optatianus Porfyrius : la métamorphose d'un genre et l'invention d'une poésie liturgique impériale sous Constantin, thèse de doctorat soutenue en janvier 1999 à Paris IV, p. 45-75: «Les poèmes à contour d'Optatien et les technopaegnia alexandrins. "

7. X, 13-19. La traduction de tous les poèmes est la nôtre.

8. Fingere Musa queat tali si carmine uultus / Augusti et metri et uersus lege manente / Picta elementorum uario per musica textu / vincere Apelleas audebit pagina ceras / Grandia quaerentur si uatis laeta Camena.

9. M.-O. Bruhat, op. cit., p. 141-146.

10. Cette dissonance n'est peut-être qu'apparente : l'expression «doux souverain de l'olympe » est une périphrase poétique (cf. VIRG. En. II, 779 ; VII, 558 ; X, 437 pour désigner Jupiter) qui peut sans difficulté s'appliquer à Dieu, et rector Olympi est une fin d'hexamètre de la poésie chrétienne.

11. III, 4-5.

12. III, 5-7.

13. III, $12-18$.

14. III, u. $i$.

15. LACT. Inst. I, 13-16. Cf. M.-O. Bruhat, op. cit., p. 212 sq.

16. XII, 3-12.

17. RIC, VI, p. 133, 137, 224, 226 etc.

18. Après 317, les émissions avec Sol sont très rares, mais M. R. Alföldi, « Die Sol comes Münze vom Jahr 325. Neues zur Bekehrung Constantins », Mullus, Festschrift T. Klauser, Münster 1964, p. 10-16, a recensé cinq émissions d'or, provenant d'ateliers différents, qui portent la légende Soli comiti Augusti nostri, et qu'elle situe, pour quatre d'entre elles, entre la fin de 324 et l'été 325, pour la cinquième entre 324 et 326. K. Aland, dans ANRW II, 23-1, «Das Zeugnis der Münzen », p. 111 sq., 
propose de voir dans ces frappes un geste de Constantin pour rassurer les classes supérieures païennes de l'Est, inquiètes devant l'imminence d'un pouvoir chrétien.

19. M. R. Alföldi, Die Constantinische Goldprägung. Untersuchungen zu ihrer Bedeutung für Kaiserpolitik und Hofkunst, Mainz, 1963, $\mathrm{n}^{\circ} 114,115,116$.

20. XIV, 1-5 ; 28-35.

21. III, 8-10: «Toi qui encourages de toutes les manières la Camène à prononcer de savantes paroles, tu accueilles radieux les vœux pour ta prospérité, afin qu'ils s'accomplissent. »

22. Lucr. Nat. III, 5-6: inque tuis nunc / ficta pedum pono pressis uestigia signis, /non ita certandi cupidus quam propter amorem / quod te imitari aueo.

23. Ibid. I, 69-74. Traduction José Kany-Turpin, Paris, GF, 1997.

24. Ibid. I, 922-930.

25. Sur la théologie de la victoire, cf. G. Ch. Picard, Les trophées romains. Contribution à l'histoire de la religion et de l'art triomphal à Rome, Paris, 1957 ; F. Heim, La théologie de la victoire de Constantin à Théodose (Théologie historique, 89), Paris, 1992 ; M. McCormick, Eternal victory : triumphal rulership in late antiquity, Byzantium, and the early medieval West, Cambridge Paris, 1986 ; sur le rituel des vœux, cf. A. Chastagnol, "Les jubilés impériaux de 260 à 337 » dans Crise et redressement dans les provinces européennes de l'Empire (milieu du IIIe - milieu du IVe siècle après J.-C.), éd. E. Frezouls, Université de Strasbourg III, 1983, pp. 11-25.

26. IV, 1-10.

27. V, u. i.

28. VIII, 1-5.

29. VIII, 34-35.

30. Ch. Pietri, «Constantin en 324 : propagande et théologie impériales d'après les documents de la Vita Constantini », dans Crise et redressement dans les provinces européennes de l'Empire, pp. 63-90.

31. Vita Constantini, II, 55, 2.

32. On trouve déjà ces thèmes orchestrés par Constantin dans la lettre qu'il adresse en 313 au vicaire d'Afrique Aelafius après le synode de Rome, lors du schisme donatiste. Appelé à arbitrer un conflit qui déchirait la concorde ecclésiale, l'empereur craignait surtout la réaction divine que ces dissentiments pouvaient provoquer : "En effet, comme je suis assuré que tu es, toi aussi, un fidèle du Dieu suprême, je confesse à ta dignité que je ne trouverais en aucune manière juste que soient négligés par nous les conflits et les disputes de cette nature, à cause desquels la divinité suprême pourrait peut-être s'émouvoir non seulement contre le genre humain, mais également contre moi-même, au soin de qui, d'un signe de sa volonté céleste, elle a confié la conduite de toutes les affaires terrestres (...). Et de fait, je pourrai être réellement et pleinement rassuré, et espérer à chaque fois de la bienveillance si prompte à s'exercer du Dieu tout puissant les plus grands succès et les plus grands bonheurs, lorsque je me serai rendu compte que tous sans exception vénèrent le Dieu très saint selon le culte de la religion catholique qui lui est dû, et dans la concorde fraternelle de l'observance. » (Optat de Milev, CSEL 26, Append. 3, p. 206, 113-23).

33. Oratio, chap. 26.

34. X, 1-6.

35. G. Polara, Commentarium, p. 56.

36. Res gestae, chap. 34. L'inscription portée sur le bouclier, qui fut reproduite sur plusieurs monuments, était la suivante: s. p. q. r. Augusto dedit clupeum uirtutis clementiae iustitiae pietatis causa. Pour l'interprétation du poème VII, cf. M.-O . Bruhat, op. cit., p. 148-150 et 182-191.

37. Pan. Lat. 9, 25, 4.

38. VII, 1-19.

39. VII, 23-35.

40. M. R. Alföldi, Die constantinische Goldprägung, $\mathrm{n}^{\circ} 141$ à 164 . On trouve les légendes Gaudium Augusti nostri, Gaudium Reipublicae, et Gaudium Romanorum. 
41. U. Ernst, Carmen figuratum..., p. 26 sq. ; U. von Wilamowitz, " Die grieschichen Technopägnia », Jahrbuch des deutschen archäologischen Instituts, 1899, p. 51-59, pensait que les trois poèmes de Simias et la Syrinx de Théocrite étaient destinés à être inscrits sur des objets votifs; $\mathrm{Ph}$. E. Legrand, Bucoliques grecs, t. 2, p. 222-225, est beaucoup plus réservé, et remarque que dans cette hypothèse, la lecture de poèmes comme la Hache et l' $E u f$ de Simias eût été singulièrement malaisée.

42. III, 29-35.

43. Cf. C. Moschetti, Gubernare nauem, gubernare rem publicam, Quaderni de Studi Senesi 16, 1966.

44. La victoire fut remportée par Crispus sur Abantus, amiral de Licinius. Vaincu près d'Andrinople le 3 juillet 324, Licinius se retira à Byzance, et nomma alors Auguste un de ses fonctionnaires, Martinien; il dut évacuer la ville et passer sur la rive asiatique du Bosphore quand la flotte que commandait Crispus eut anéanti la sienne et bloqué l'entrée de l'Hellespont ; il subit une défaite décisive près de Chrysopolis et se rendit quelques semaines plus tard.

45. G. Polara, Commentarium, p. 120 ; A. Piganiol, L'empire chrétien, $2^{\mathrm{e}}$ éd. Remise à jour par A. Chastagnol, Paris, 1972, p. 19, cite le texte de l'Expositio totius mundi, 28, qui présentait Ascalon et Gaza comme in negotio bullientes; Eusèbe (VC IV, 38) mentionne le fait que Gaza fut agrandie par Constantin et appelée Constantia, du nom de la sœur de l'empereur.

46. Vita Constantini, I, 8 et IV, 7.

47. J.-P. Martin, Providentia deorum. Recherches sur certains aspects religieux du pouvoir impérial romain, École Française de Rome, 1982, p. 353.

48. RIC II, p. 433 et planche XV, $\mathrm{n}^{\circ} 315$; Cohen, II, p. 166, n708, cf. pl. 1.

49. RIC III, Marc-Aurèle : p. 307 et pl. XIII, n²54 ; L. Vérus : pp. 319-320, n¹325sq.

50. J.-P. Martin, Providentia deorum, p. 328 et 352. Ces monnaies furent frappées entre déc. 162 et l'automne 163, à l'occasion d'une expédition militaire destinée à rétablir la frontière orientale de l'empire, et la promesse de Félicité s'inscrit là dans un contexte de reconquête.

51. RIC III, p. $334, \mathrm{n}^{\circ} 1513$.

52. RIC III, p. 422 et pl. XVI, n³31.

53. A. Alföldi, "A festival of Isis in Rome under the christian Emperors of the IVth Century », Dissertationes Pannonicae 2, 7, Budapest, 1937, p. 56.

54. RIC VII, $\mathrm{n}^{\circ} 301$ p. 332.

55. RIC VII, p. $572, \mathrm{n}^{\circ} 18$ et p. $573, \mathrm{n}^{\circ} 19 ;$ planche $18, \mathrm{n}^{\circ} 18$.

56. RIC VII, p. 567.

57. Optatien innove également en fusionnant la valeur chrétienne du navire dont le mât est figuré par la croix et la valeur jusque là païenne du navire comme symbole du charisme impérial. Pour la valeur chrétienne, cf. J. Daniélou, Les symboles chrétiens primitifs, Paris, 1961, chap. IV : « Le navire et l'Église ». Hippolyte de Rome, Traité sur l'Antéchrist, 59, 1, propose l'interprétation suivante de la représentation du navire avec croix : «La mer est le monde. L'Église, comme un navire, est secouée par les flots, mais non submergée. Elle a en effet avec elle un pilote expérimenté, le Christ. Elle a en son milieu le trophée vainqueur de la mort, comme si elle portait la croix du Christ avec elle. » On voit bien que le symbolisme du navire d'Optatien, en substituant à la croix le chrisme constantinien, revient à transposer cette interprétation spirituelle et ecclésiale dans le registre politico-religieux de la célébration de l'empereur chrétien. Nous avons montré (cf. notre thèse p. 320-324) qu'Optatien est pionnier dans ce domaine. Lactance, dans le De ira dei, recourt à l'image du navire et de son pilote pour illustrer le gouvernement unique de Dieu $(11,4)$, Eusèbe, dans la Vita Constantini, utilise la même image pour illustrer le gouvernement unique de Constantin : "Comme tous les peuples, en tous lieux, étaient à l'image d'un navire, confiés à la maîtrise d'un seul pilote et s'en remettaient au pouvoir et à la religion du serviteur de Dieu, tous menaient une vie tranquille et paisible. » (IV, 14) Il s'agit pour Eusèbe de montrer qu'au gouvernement spirituel unique de Dieu correspond le gouvernement temporel unique de Constantin. Optatien a anticipé cette leçon et l'a mise en image. 
58. Quint. Inst. I : ... permittamus uela uentis et oram soluentibus bene precemur. Il s'agit de la lettre adressée par Quintilien à Tryphon, éditeur-libraire, pour lui confier la publication de l'Institution oratoire. Traduction J. Cousin, Institution oratoire, t. 1, Paris, Belles Lettres, 1975, p. 48.

59. Sur cette question, état de la question dans notre thèse, p. 23-31. Notre perplexité reste grande. G. Polara, Carmi di Publilio Optaziano Porfirio, Torino, 2004, p. 43-44, tient les lettres pour des faux d'époque médiévale.

60. Ep. Porfyrii : Quid ego faciam tenui pauper ingenio, meriti nunc usque perparui? Caelestis iudicii dignatione inmensum pondus impositum est eius imperatoris testimonio, qui inter belli pacisque uirtutes, inter triumphos et laureas, inter legum sanctiones et iura etiam Musis tibi familiaribus plaudis, ut inter tot diuinae maiestatis insignia, quibus et inuictus semper et primus es, huius etiam studii in te micet splendor egregius. (...) Etenim si, ita ut sapientibus placuit, maxime imperator, aestimanda sunt, non numeranda iudicia, qui huiusmodi testimonium consecutus sum pietatis tuae dignatione caelesti, iam licet Parnasi iuga securus ingrediar et ab ipsis Aonii uerticis adytis deducere audeam Musas, tutus, quacumque mens ibit in carmina.

61. Ep. Constantini: Pro qualitate modulaminis ad singulos quosque expetitae laudis gratia redundauit. Defuit quorundam ingeniis temporum fauor, qui non secus doctrinae deditas mentes inrigare atque alere consueuit quam si cliuosi tramitis supercilio riuus elicitus scaturrientibus uenis arua arentia temperauerit. Saeculo meo scribentes dicentesque non aliter benignus auditus quam lenis aura prosequitur; denique etiam studiis meritum a me testimonium non negatur. Liber assidue cursus orationibus fuit; eos uero qui uersibus dicerent certis finibus lex metris statuta continuit : quare non inmerito illud usus inuenit, ut hoc genere dicturis Heliconis aut Parnasi sacra peterentur, cum mortalis ingenii deficiente substantia necessaria uiderentur auxilia diuina.

62. Vita Constantini, IV, 9, 13. Cf. F. Heim, La théologie de la victoire de Constantin à Théodose, Théologie historique 89, Paris, 1992.

63. Cf. D. de Decker, « Le « Discours à l'assemblée des saints » attribué à Constantin et l'œuvre de Lactance » dans Lactance et son temps, Actes du IV Colloque d'études historiques et patristiques de Chantilly (21-23 septembre 1976), éd. J. Fontaine et M. Perrin, p. 77-87 ; R. Lane Fox, Païens et chrétiens. La religion et la vie religieuse dans l'empire romain de la mort de Commode au concile de Nicée, trad. française, Toulouse, 1997, p. 650 sq. L'Oratio ad sanctorum coetum est présenté et traduit par M. Edwards dans Constantine and Christendom, Liverpool University Press, 2003.

64. D. de Decker, op. cit., p. 84.

65. Oratio, 10.

66. LACT. Inst., I, 11, 22-38.

67. Oratio, 10.

68. Sur la question, cf. les pages consacrées à Lactance par J. Fontaine, Naissance de la poésie chrétienne dans l'Occident chrétien, Paris, Études augustiniennes, 1981 («Lactance et la mue de l'oiseau phénix au siècle de Constantin», p. 53-66); P. A. Deproost, "Ficta et facta. La condamnation du 'mensonge des poètes' dans la poésie latine chrétienne ", Revue des Études Augustiniennes, 44, 1998, p. 101-121, montre bien comment, derrière le topos du mensonge poétique, s'exprime au contraire une filière de confiance dans la capacité de la parole poétique à dire la vérité. La rupture parfois proclamée bien haut avec les Muses ne doit pas occulter la réalité d'une conversion des valeurs antiques de l'inspiration poétique à la foi chrétienne.

69. Oratio, 18.

70. CIC. de diu. 2, 54.

71. Sur ces questions, cf R. Lane Fox, op. cit. p. 652 sq. ; N. Wigtil, «Toward a Date for the greek fourth Eglogue », Class. Jour., 76, 1981, pp. 336-341; L. Coronati, «Osservazioni sulla traduzione greca della IV ecloga di Virgilio », Civiltà classica e cristiana, 5, 1984 p. 71-84.

72. Oratio, 19.

73. Ibid., 20. 
74. Sur ce point, cf. M.-L. Guillaumin, «L'exploitation des « Oracles Sibyllins » par Lactance et par le « Discours à l'assemblée des saints », dans Lactance et son temps, p. 185-200.

75. Ibid., 2.

76. Ibid. 26.

77. J. Scheid-J. Svenbro, Le métier de Zeus, mythe du tissage et du tissu dans le monde gréco-romain, Paris, La Découverte, 1994, p. 45 (réédition Paris, Errance, 2003)

78. Pan. Lat. 7, 21, 4 : Vidisti enim, credo, Constantine, Apollinem tuum comitante Victoria coronas tibi laureas efferentem, quae tricenum singulae ferunt omen annorum.

79. A. Alföldi, The conversion of Constantine and pagan Rome, Oxford, 1948 : p. 58, il évoque les nombreuses fois où Eusèbe compare Constantin à l'astre solaire, et souligne que les cas sont encore plus fréquents «chez un poète chrétien qui écrit en latin, Optatianus Porphyrius. » Cf. aussi P. Bruun, "The disappearance of Sol from the coins of Constantine", dans Studies in Constantinian numismatics, 1958, pp. 37-48 ; R. Leeb, Konstantin und Christus : die Verchristlichung der imperialen Repräsentation unter Konstantin dem Grossen als Spiegel seiner Kirchenpolitik und seines Selbstverständnisses als christlicher Kaiser, Berlin-New-York, 1992, p. 23-26 ; M. Wallraff, Christus uerus Sol: Sonnenverehrung und Christentum in der Spätantike, Münster, 2001. Sur les visions successives de Constantin, R. Turcan, Constantin en son temps. Le Baptême ou la Pourpre?, Éditions Faton, Dijon, 2006, p. 132-162.

80. Dans la Vita Constantini, I, 43, Eusèbe décrit comme une épiphanie solaire l'apparition de l'empereur sortant le matin de son palais. Et dans le Triakontaétérikos, discours pour les trente ans de règne de Constantin, l'évêque de Césarée décrit le rôle des Césars comme des prolongements de leur père à travers l'image solaire : «L'empereur, comme le fait le soleil par ses scintillements, illumine par ses rayons que sont les Césars les habitants des régions les plus lointaines : ici même, à nous qui peuplons l'Orient, il a attribué un fils digne de lui ; puis un second à une autre partie de l'univers, et un troisième encore ailleurs, qui, comme des flambeaux et des astres, diffusent la lumière qui émane de lui. »

81. Paulin De Nole, Carmina, 10, 20-23: Quid abdicatas in meam curam, pater / redire Musas praecipis? / Negant Camenis, nec patent Apollini / dicata Christo pectora. Cf. D. Amherdt, Ausone et Paulin de Nole: correspondance. Introduction, texte latin, traduction et notes, Peter Lang, Berne, 2005.

\section{RÉSUMÉS}

La majorité des poèmes d'Optatianus Porfyrius qui nous sont parvenus est dédiée à l'empereur Constantin et consacrée à son éloge. Mais dans cette poésie visuelle d'un nouveau genre, la célébration de l'art poétique tient une place aussi importante que la célébration impériale. Comment considérer le discours proprement poétique d'Optatianus ? Est-il simplement juxtaposé au discours politique? Relève-t-il d'une pure convention ornementale? Ces questions sont d'autant plus pertinentes que, loin de présenter le procédé visuel dont il est l'inventeur comme un art technicien, Optatianus revendique le double titre de poiètès et de uates et convoque les divinités de l'inspiration, Phébus et les Muses, alors même que ses poèmes se font l'écho de la nouvelle théologie chrétienne du pouvoir. La réponse apparaît double. D'une part, la poésie d'Optatianus peut être définie comme votive. Ses poèmes s'inscrivent dans la liturgie du pouvoir, c'est-à-dire dans le cadre d'une théologie impériale qui repose sur l'affirmation de l'éternité de la victoire et sur le renouvellement du charisme victorieux à travers le rituel des voeux. Par son 
discours sur Phébus et les Muses, Optatianus met en place une véritable poétique du voeu, qui consiste à couler la mystique de l'inspiration dans le moule de la mystique impériale. D'autre part, ce projet poétique répond à bien des égards à l'attente impériale. Il rencontre la volonté de Constantin de développer une politique culturelle, et se plie à quelques traits caractéristiques de sa religiosité : conviction de la nécessité du secours divin dans les actions humaines, d'une inspiration divine dont Constantin a fait lui-même l'expérience, attention aux signes et aux visions, attachement à un charisme solaire qui coexiste sous une forme «neutralisée » avec sa foi chrétienne. Le poème XIX, composé à l'occasion de la deuxième célébration des Vicennales à Rome en juillet 326, est l'illustration accomplie d'une réflexion poétique dont la genèse est intimement liée à l'objet idéologique de la poésie.

INDEX

Mots-clés : culte des Muses, inspiration, mystique impériale, Optatianus Porfyrius, poème figuré, rituel, voeux, poétique

\section{AUTEUR}

\section{MARIE-ODILE BRUHAT}

marie-odile.bruhat@orange.fr 